\title{
Key Regulatory Issues in Nuclear Microreactor Transport and Siting
}

September 2019

The INL is a

U.S. Department of Energy National Laboratory

operated by

Battelle Energy Alliance

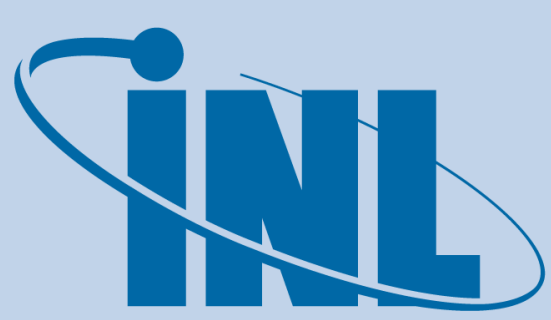

Idaho National Laboratory 


\section{DISCLAIMER}

This information was prepared as an account of work sponsored by an agency of the U.S. Government. Neither the U.S. Government nor any agency thereof, nor any of their employees, makes any warranty, expressed or implied, or assumes any legal liability or responsibility for the accuracy, completeness, or usefulness, of any information, apparatus, product, or process disclosed, or represents that its use would not infringe privately owned rights. References herein to any specific commercial product, process, or service by trade name, trade mark, manufacturer, or otherwise, does not necessarily constitute or imply its endorsement, recommendation, or favoring by the U.S. Government or any agency thereof. The views and opinions of authors expressed herein do not necessarily state or reflect those of the U.S. Government or any agency thereof. 


\title{
Key Regulatory Issues in Nuclear Microreactor Transport and Siting
}

September 2019

\author{
Idaho National Laboratory \\ INL ART Program \\ Idaho Falls, Idaho 83415
}

http://www.inl.gov

Prepared for the

U.S. Department of Energy

Office of Nuclear Energy

Under DOE Idaho Operations Office

Contract DE-AC07-05ID14517 

INL ART Program

Key Regulatory Issues in Nuclear Microreactor Transport and Siting

INL/EXT-19-55257

September 2019

Author:
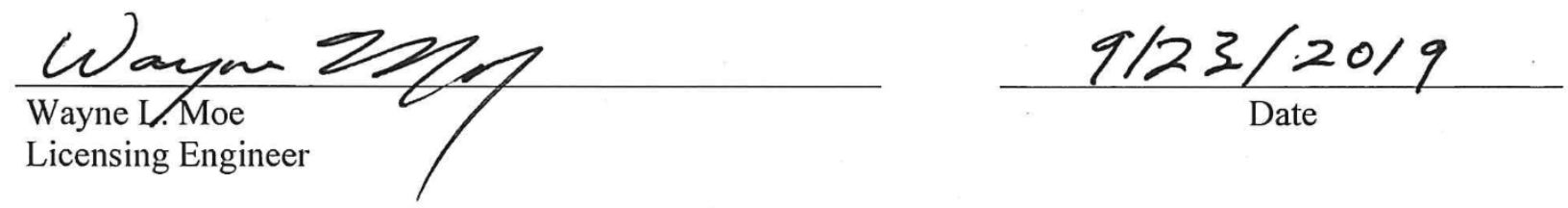

Approved by:
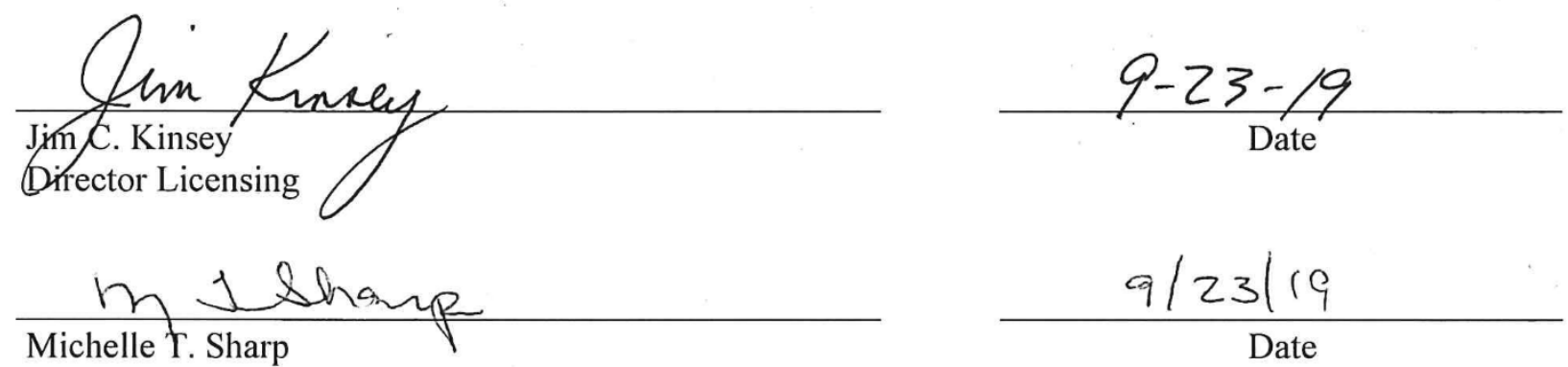

INL Quality Assurance

$\frac{9 / 23 / 19}{\text { Date }}$ 



\section{SUMMARY}

Inherent and passively safe nuclear microreactors are being developed that feature mobility and autonomous operations much different from the current fleet. If suppliers succeed in attaining stated design objectives, numerous commercial, industrial, and military applications will open for this technology. Challenges in flexibly licensing and deploying such systems are foreseen, especially in areas related to rapid site acceptance and reactor module transport. New assessment approaches will be needed if microreactors are to realize their full commercial use potential.

This report examines some foundational regulatory concerns related to microreactor transport and siting in the continental U.S. Three deployment scenarios were developed to support a basic regulatory structure needs analysis. The review focused on major microreactor technology attributes, management of fueled and unfueled modules during transport, and enhanced siting independence. Report recommendations that are suggested as suited for immediate action include:

- Encourage and participate in stakeholder interactions during the ongoing emergency planning rulemaking to ensure scaled off-site emergency planning appropriate to microreactor transport and operations is addressed. Ensure 16 emergency planning standards are appropriately updated.

- Address identified issues with 10 Code of Federal Regulations (CFR) Parts 71 and 73 to determine transport and physical protection requirements for high assay low-enriched uranium (HALEU) fuel throughout the entire deployment life cycle

- Define and address challenges associated with microreactor physical protection during transport and siting

- Develop a new qualified "Type B" transportation packaging configuration that enables fueled vessel mobility and transport

- Streamline site characterization and environmental report requirements by refocusing safety and impact assessment criteria on site elements unique to microreactor risk and safety

- Develop a position for establishing U.S. Nuclear Regulatory Commission (NRC) jurisdictional boundaries for microreactor siting (e.g., repowered fossil fuel plants, municipalities, collocated industrial facilities, etc.)

Additional report recommendations include:

- Develop HALEU criticality benchmark data to support licensing decisions

- Assess the extent to which the inspections, tests, analyses, and acceptance criteria (ITAAC) program must be amended to support microreactor transport and temporary deployment

- Develop general design criteria that address fueled module mobility and transport

- Develop a generic environmental impact statement to inform major federal decisions in future microreactor siting actions 
- Ascertain the level to which Federal Energy Regulatory Commission (FERC) reliability standards apply to isolated microgrids and establish a means by which customers can accommodate microreactor license conditions

To support site characterization and permit process streamlining, a microreactor site permit-by-rule (PBR) concept has been proposed whereby sites could be evaluated and accepted in advance using assumptions and requirements established under bounding plant and (hypothetical) site parameter envelopes. If microreactor technology can demonstrate sufficient safety in all modes of designed operation, envelope-based siting assessments could be made a part of an existing early site acceptance program in order to reduce bureaucratic burdens without sacrificing public safety. 


\section{CONTENTS}

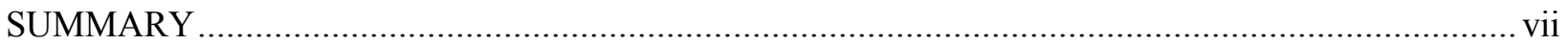

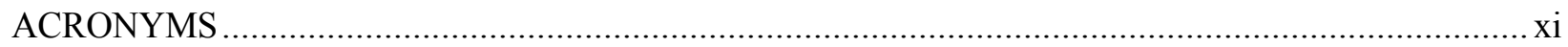

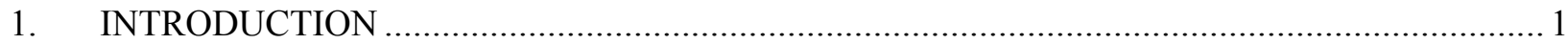

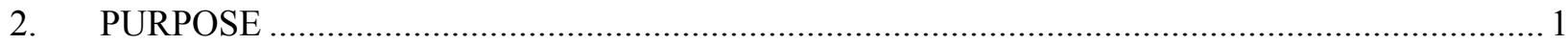

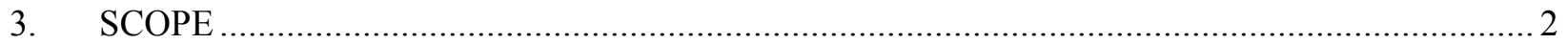

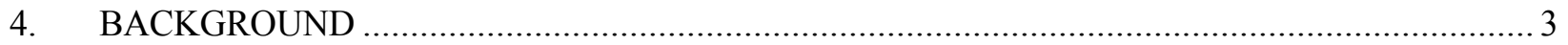

4.1 General Microreactor Design Characteristics ................................................................ 3

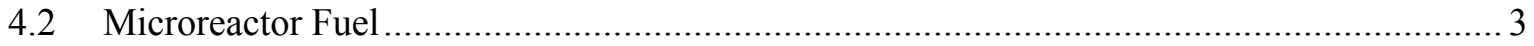

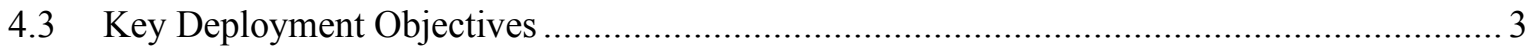

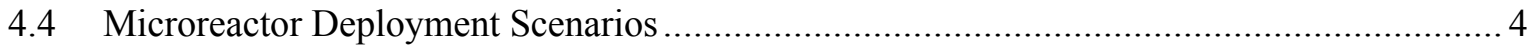

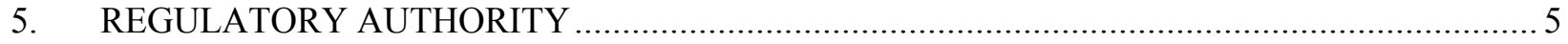

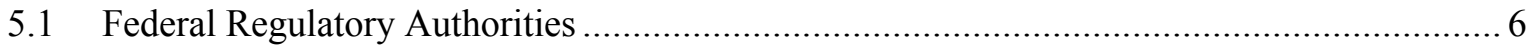

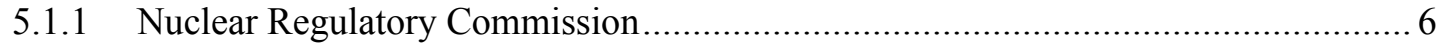

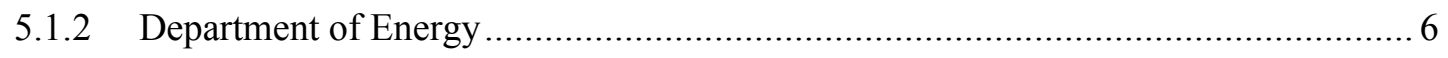

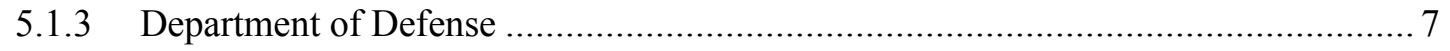

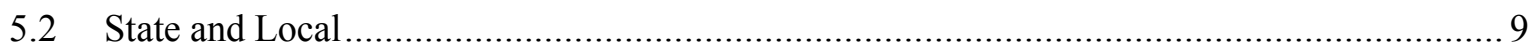

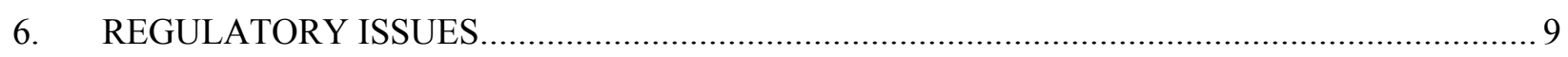

6.1 Microreactor-module Transportation ........................................................................ 9

6.1.1 Fuel Loading at Reactor Manufacturing Facility ............................................. 9

6.1.2 Physical Security During Transport ............................................................. 13

6.2 Transport of Operated Microreactor Modules to New Operational Sites ........................... 13

6.2.1 Site-to-Site Microreactor Transport .............................................................. 14

6.2.2 Reactor Startup and Restart Testing Requirements for Site-specific ITAAC .......... 17

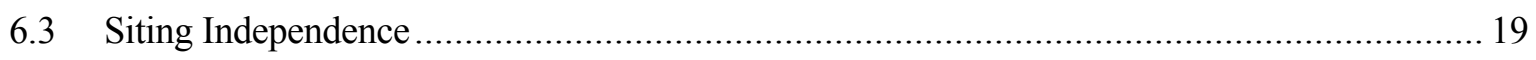

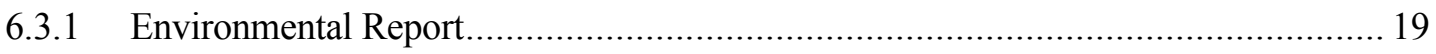

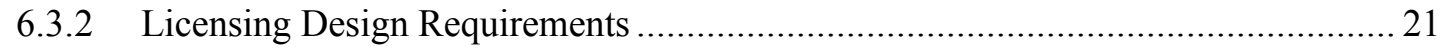

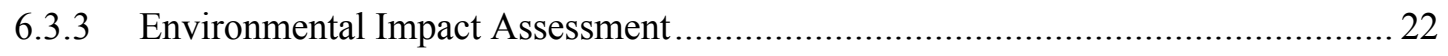

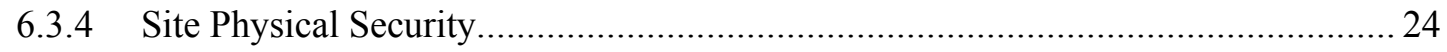

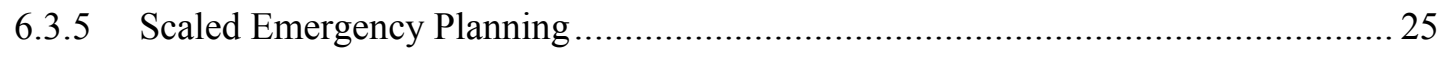

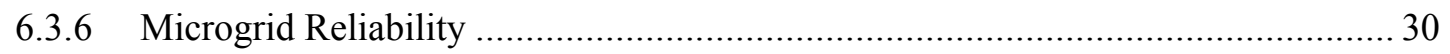

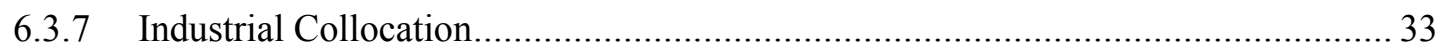

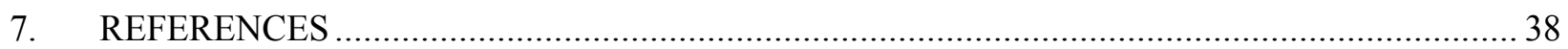

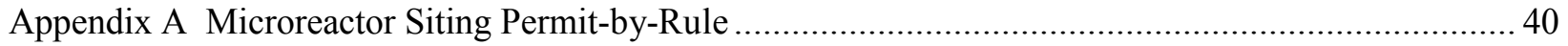




\section{FIGURES}

Figure 1. Example size scale of a proposed microreactor design......................................................... 2

Figure 2. Considerations in military microreactor applications. ....................................................... 8

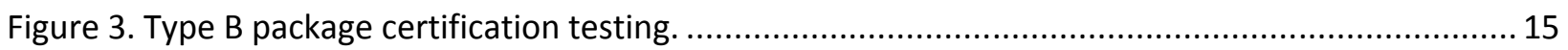

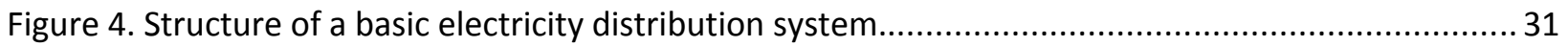

Figure 5. The Westinghouse eVinci microreactor design concept. .................................................. 34

Figure 6. Some typical industrial heat requirements by industry type and exit temperature. ................ 35

\section{TABLES}

Table 1. Transportation casks currently licensed by NRC.

Table 2. Microreactor considerations in 10 CFR 50.47 emergency planning standards. 


\section{ACRONYMS}

$\mathrm{AC} \quad$ alternating current

ACRS NRC Advisory Committee on Reactor Safety

AEA Atomic Energy Act

ARDC advanced-reactor design criteria

ART Advanced Reactor Technologies

CEQ Council on Environmental Quality

CFR Code of Federal Regulations

COL combined (operating) license

DOE U.S. Department of Energy

DBT design basis threat

DC design certification

DoD Department of Defense

DOE Department of Energy

DOT Department of Transportation

EAB exclusion area boundary

EIS Environmental Impact Statement

EOF emergency operations facility

EP emergency planning

EPZ emergency planning zone

ER environmental report

ERO electrical reliability organization

ESP early site permit

FEMA Federal Emergency Management Agency

FERC Federal Energy Regulatory Commission

FFTF Fast Flux Test Reactor

FSAR final safety analysis report

GDC general design criteria

GEIS Generic Environmental Impact Statement

HALEU high-assay low enriched uranium

ICN ITAAC closure notification

INL Idaho National Laboratory

ISG interim staff guidance

ITAAC inspections, tests, analyses, and acceptance criteria 
$\mathrm{KW}(\mathrm{t}) \quad$ kilo-watt thermal

LEU low enriched uranium

LOOP loss of off-site power

LWR light water reactor

MW(e) mega-watt electrical

MW(t) mega-watt thermal

NEI Nuclear Energy Institute

NELA Nuclear Energy Leadership Act

NEPA National Environmental Policy Act

NERC North American Electric Reliability Corporation

NRC U.S. Nuclear Regulatory Commission

ONT other new technology

PBR permit-by-rule

PDC principal design criteria

PPE plant parameter envelope

PWR pressurized water reactor

R\&D research and development

RG regulatory guide

SEIS Supplemental Environmental Impact Statement

SMR small modular reactor

SNM special nuclear material

SPE site parameter envelope

SRM staff requirements memoranda

SSC structures, systems and components

TSC technical support center

U.S. United States of America

USC United States Code 


\section{Key Regulatory Issues in Nuclear Microreactor Transport and Siting}

\section{INTRODUCTION}

A growing number of very small power-reactor concepts, colloquially identified as "microreactors," are currently being developed for commercial and non-commercial purposes in the U.S. and the rest of the world. These thermal and fast-neutron units are being pursued as a reliable and versatile solution to a number of specialized energy-supply challenges that encompass a wide variety of civilian and military applications. The potential customer base for electric and heat energy from microreactors include remote mining operations, off-shore platforms, communication stations, isolated residential communities, and permanent and expeditionary military bases. They have also been envisioned as an ultra-mobile response option to natural disasters and other infrastructure disruptions.

In past decades, the U.S. Department of Energy (DOE) supported a number of key research and development (R\&D) activities needed to move advanced (i.e., non-light-water) reactor technology closer to design maturation and commercial viability. These include gas-cooled, liquid-metal, molten-salt, and heat-pipe-cooled reactor designs. Very recently, DOE expanded its R\&D role to include microreactor technologies as a new developmental priority, with the goal of enabling suppliers the opportunity to license and deploy the technology to help meet the nation's energy needs. While arrays of conceptual design options have emerged from aspiring vendors, most domestic suppliers are trending towards gasand heat-pipe-cooled fission reactor variants that could operationally debut (as prototypical demonstration platforms) as early as the mid-2020s [1].

\section{PURPOSE}

If these new designs can be demonstrated as sufficiently safe and efficient, the advent of microreactors for industrial and non-industrial applications could lead to a dramatic shift in the way nuclear technology is employed to generate electricity and process heat. Small overall dimensions (see Figure 1), intrinsic and passive safety features, portability, and use of non-water coolants to dissipate residual core heat under all normal and off-normal design conditions could enable their use in new and novel ways. Nuclear reactor operations are tightly regulated and licensed in the U.S., however, if microreactor technology is to be a viable energy market component, an increasingly nimble system of safety assessment, licensing, and regulatory oversight may be needed.

Streamlined site evaluations, along with simple and innovative methods by which risk receptor protection can be assessed during unit transport and site operations, will likely need to be developed to support technology deployment objectives. Given the unprecedented level of mobility and transportability that will be hallmark of the microreactor fleet, certain elements of the U.S. regulatory environment may need to be developed without benefit of having an established regulatory precedent.

At a minimum, the innovations and features that enable microreactor mobility and operational flexibility must meet or (preferably) exceed existing public-safety and security standards applicable to contemporary nuclear power stations. This report examines of some key regulatory-transformation issues that are believed to be critical in future commercial microreactor deployments. Discussed topics focus on high-level regulatory issues related to nuclear-module mobility, transport, and siting. These are topics of particular significance because the current regulatory framework does not currently offer clear safetyperformance objectives, assessment processes, and acceptance criteria related to mobile fully operational reactor units at impermanent locations. 


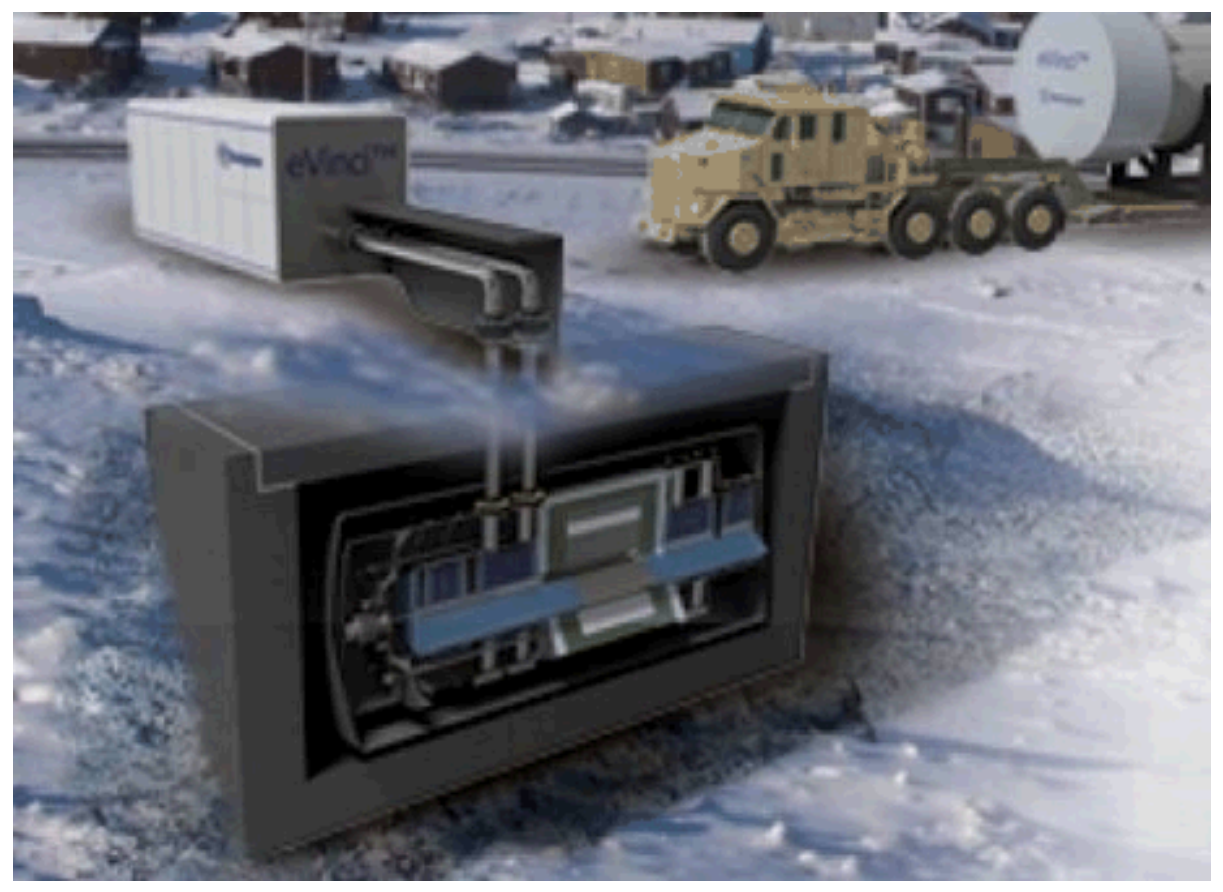

Figure 1. Example size scale of a proposed microreactor design.

This report offers some initial observations and top-level recommendations on options that should be considered when inaugurating the planning necessary to move reactor licensing processes towards compatibility with microreactor technologies.

\section{SCOPE}

Contemporary interest in microreactors has spread across a spectrum of economic opportunities. This includes direct residential, industrial, and military applications, use as a back-up for solar- and windenergy production, and other applications with relatively small electrical loads and/or heating needs. Support of domestic and foreign Department of Defense (DoD) locations (like secure military bases and mobile support to expeditionary forces) are contenders for initial microreactor use.

A comprehensive regulatory analysis of potential licensing challenges associated with such a broad array of potential deployment situations is difficult to perform when the technology itself is still evolving in terms of design safety. Despite this, certain attributes can be predicted as characteristic of emerging microreactor designs. On this basis, certain high-level regulatory challenges can be identified and preliminarily evaluated; these issues include microreactor mobilization, transport, and expedited site permitting.

A brief description of design and deployment characteristics important to regulatory framework considerations are provided in Section 4. A summary of potential options in domestic oversight and licensing authority is provided in Section 5 of this report. Analysis and recommendations provided in this report assume a base-case regulatory authority as the U.S. Nuclear Regulatory Commission (NRC) and associated agencies such as the Department of Transportation (DOT), where appropriate. Regardless of the involved regulatory authorization entity, however, the complexities and interactive nature of licensing a working nuclear reactor will require continuous interactions between industry, the public, and technical staff of all potentially affected regulatory agencies.

Sections 6.1 and 6.2 examine top-level regulatory issues associated with microreactor transportation. Section 6.3 explores key site fundamentals like permitting, microgrids, and jurisdictional authority at collocated locations. Recommendations on possible "next steps" are provided in each subsection. 


\section{BACKGROUND}

\subsection{General Microreactor Design Characteristics}

To minimize costs and maximize utilization, microreactor developers are planning to incorporate new features and performance goals that greatly enhance transportability, automated operational responses, and capabilities. These capabilities include coupling reactor modules to ultra-compact power-conversion systems like Sterling engines, supercritical $\mathrm{CO}_{2}$ cycles, or other direct-conversion devices. While performance specifications will vary greatly between individual designs, the definition of microreactor as a technology class is not based on fundamental design similarities. Contrary to longstanding industry nomenclature, microreactors will likely not (at least initially) be classed on the basis of commonalities in fuel form or coolant system. Instead, microreactors are understood to possess the following features:

- Factory fabrication. Critical microreactor components will be fabricated and assembled in a factory for subsequent shipment to an alternate location for field use. Factory assembly reduces or eliminates many difficulties associated with large-scale field construction and enhances opportunities for increased quality control measures during manufacture. Modularization of microreactor units may be pursued to further facilitate factory fabrication approaches.

- Transportability. Small dimensions and a robust design make microreactors feasible for ready transport and mobility. This includes contingencies for sealed modules where the entire (i.e., fully fueled) reactor assembly can be relocated by truck, vessel, railcar, or aircraft.

- Self-regulating. Successes in simple design and passive and inherent safety may lead to opportunities for semiautonomous operations and self-response within a robust, well-defined safety envelope.

Coupled with small radiological source terms, it is possible that fundamental microreactor design could preclude the plausibility of a reactor-core overheat that leads to core damage. Such designs are not projected to require large on-site staff to support operations or provide protective security to the plant. Module maintenance may be accomplished by periodic transport back to a factory for inspection and refurbishment.

As a technology, microreactors will likely be able to produce from a few hundred $\mathrm{KW}(\mathrm{t})$ up to $20 \mathrm{MW}(\mathrm{t})$ from a long-life core that operates from 3 to 10 years without refueling. Some suppliers are working to create "plug and play" operational patterns that allow quick reactor-module changeouts with new modules, which would then be followed by reactor-vessel transport (containing spent nuclear fuel) back to the factory for defueling and spent fuel storage.

\subsection{Microreactor Fuel}

In the United States, commercial light-water reactors (LWRs) generate electricity using low-enriched uranium (LEU) fuel. Low-enriched uranium has uranium- 235 content greater than $0.7 \%$ and less than 20\%. Today's LWR fleet uses LEU with uranium-235 levels less than 5\%. Some advanced reactors and advanced LWRs are now being designed to utilize LEU with uranium-235 levels between 5\% and 20\%. Fuel manufactured from uranium-235 enriched to levels between $5 \%$ and $20 \%$ is referred to as high-assay low-enriched uranium (HALEU) fuel and can improve fuel utilization and support better overall plant economics. With the development of advanced-reactor technology, both newly constructed and operating power reactors will need HALEU fuel. The U.S. nuclear fuel-cycle infrastructure has not yet been modified to provide new sources of HALEU as well as qualified packaging that enables HALEU transport [2].

\subsection{Key Deployment Objectives}

To better appreciate the complexity of regulatory issues associated with characteristics as discussed in Subsection 4.1, it is also necessary to understand deployment objectives of the industry. A summary of technology objectives important to military microreactor applications was released in 2016 by an expert 
panel commissioned by the DoD [3]. This report provides an initial list of performance objectives desired by military planners which technology developers can use in formulating microreactor designs. Assuming these and similar objectives expressed by military planners since that time adequately encompass the deployment profile of non-military markets, the assessment capabilities of a licensing framework can be estimated using the following deployment parameters:

- Outputs. Modular and scalable units capable of 1-20 MW(t) and useful heat at levels that facilitate water or fuel production and a threshold power generation of 1-10 MW(e).

- Deployability. Ability to emplace a unitized system in new and diverse environments and meet all applicable rules, regulations, population-protection measures, and environmental sensitivities. Minimal site footprint required.

- Size and transportability. Ability to get system in and out of locations using currently available transport systems (i.e., 20- or 40-foot CONEX box and 25-40 tons would enable consideration of truck or aircraft transport).

- Ultimate heat sink. Ambient-air passive cooling (water cooling could constrain deployment options).

- Time to install. Proposals can vary from a few days to a few weeks.

- Refueling. Should not require more than annual refueling. Fresh and used fuel should be transportable by air, sea, and ground. Spent fuel should be stored at a central off-site location.

- Time for planned shutdown, cool down, disconnect, and removal. A few days to a few weeks.

- Operation. Simple autonomous or semiautonomous operation, minimal staff monitors overall unit health and performance. Minimal maintenance and logistic support capabilities needed. Minimal downtime matched with maximum operational availability.

- Response to emergency. Capable of immediate shutdown and passive cooling in the event of site disruption, abandonment, and hostile occupation. Resilience - i.e., the ability to avoid, prepare for, minimize, adapt to, and recover from energy disruptions and ensure energy availability and reliability sufficient for mission assurance and essential readiness - is a primary requirement for DoD use.

- Health and safety risks. No net increase in risk to public, operational personnel, or environment. All design-basis events are survivable with no net increase in consequences in the event of attack by adversary.

- Proliferation risk. No net-significant increase in weapons proliferation risk.

A licensing framework capable of addressing reactor unit mobility, fueled reactor vessel transport, and highly autonomous operations must incorporate new safety assessment and oversight capabilities in addition to adapting the methods and techniques currently available for permanent and stable LWR operations.

\subsection{Microreactor Deployment Scenarios}

Most nuclear regulation and guidance in the U.S. were crafted to support large LWRs dedicated to base-load commercial electric-power generation. Major updates to non-LWR compliance guidance have recently become available [4,5]. However, additional regulatory provisions and guidance will be needed to support the licensing of microreactors. The development of new guidance will be especially challenging concerning the movement of fueled reactor-modules to and from dispersed use sites. No existing safety-assessment methodologies or regulatory-acceptance criteria have been yet demonstrated as competent for use in assessing the safety of a fully fueled microreactor module during transport and module mobilization/demobilization at very remote sites. 
For purposes of conducting a licensing-needs analysis, the following deployment scenarios were established as a basis for consideration:

A. Module transport from factory to multiple use sites for commercial purposes. This scenario postulates an itinerant microreactor-deployment schedule that start with a factory-built (and likely factory-fueled) module and subsequent shipments to other locations for temporary use before being returned to the factory for defueling and refurbishment. Because these modules are transiently used at one or more locations for relatively short periods of time, risk factors presented to site surroundings by module operations should be lowered due to shorter periods of risk exposure. However, mobilization, demobilization, and transportation will create new risk elements that require analysis and possible mitigation.

Because Scenario A presumes an ultra-mobile fueled reactor module capability, reactor refueling and spent fuel storage can be assigned to a centralized location, thereby reducing site infrastructure support dealing with outage, maintenance, and fuel-storage capabilities.

Pursuant to 10 CFR 50.22, such a facility would be deemed commercial and subject to NRC licensing and regulatory oversight.

B. Module transport from a factory to a single-use site, followed by periodic like-for-like change-outs at the site for commercial purposes. This scenario presumes a permanent location that relies on microreactor energy for long periods of time. On-site refueling may be considered a normal field operation but plug-and-play module change-outs could also be considered where identical modules in single- or multi-module arrangements are periodically replaced.

These sites would be exposed to reactor operational-risk factors for decades, thus suggesting a more in-depth site characterization and event mitigation effort may be needed when compared to transient installations. Modules may or may not be transported back to the factory for refueling but plug-and-play deployment strategies would allow for factory refueling rather than refueling as part of normal site operations. Field-outage and maintenance resource requirements may be equal to or greater than Scenario A.

Pursuant to 10 CFR 50.22, such a facility would be deemed commercial and subject to NRC licensing and oversight authority.

C. Module transport to a permanent or transient site with eventual return to the factory; modules are used for non-commercial purposes. There are allowances for DOE and DoD regulatory authorization in non-commercial nuclear-technology applications. Pursuant to 10 CFR 50.22, such facilities would be deemed non-commercial (and therefore not subject to NRC regulation) provided less than 50 percent of the annual cost of owning and operating the facility is devoted to the production of materials, products, or energy that is not sold or commercially distributed, or is otherwise dedicated to R\&D or education and training.

Any microreactor module manufactured and fueled at a factory would need a license. Because a module manufacturing facility would likely be a commercial enterprise, the facility would need an NRC license to fuel microreactor units. Furthermore, if any modules manufactured at the facility were to eventually be licensed under NRC construction and operation license, the factory would need a NRC manufacturing license to cover the module fabrication process.

\section{REGULATORY AUTHORITY}

Microreactors are expected to be designed, manufactured, owned and operated with equipment and services that produce wholesale energy to users in niche applications and atypical use settings. Greater understanding about the likely operational settings of microreactors is important when identifying the regulatory oversight authority for the technology. At this time, three federal nuclear-technology 
regulatory and licensing or authorization authorities are available within the U.S. These entities are discussed in the following subsections.

\subsection{Federal Regulatory Authorities}

\subsubsection{Nuclear Regulatory Commission}

Established in 1974, the Nuclear Regulatory Commission is an independent government agency responsible for licensing civilian nuclear material and technology within the U.S. NRC currently regulates commercial nuclear power reactors, research and test reactors, decommissioning and waste management activities, uranium-recovery facilities, fuel facilities, and radioactive-materials users. This authority extends to activities directly overseen by 37 states that have agreements with NRC to assume regulatory responsibility for use of certain radioactive materials.

NRC regulates commercial nuclear activities in order to ensure "adequate protection to the health and safety of the public" and "in accord with the common defense and security"; these requirements are set by the Atomic Energy Act (AEA) as a minimum safety standard followed by NRC activities. Congress provides great discretion to the Commission (on a case-by-case basis) when exercising its authority in determining what constitutes "adequate protection." Determinations of compliance made by the agency rely heavily on expert engineering and scientific judgments and, considering all relevant information available to the agency, applicants are expected to pursue nuclear-technology improvements over time.

NRC also has licensing and oversight authority for certain nuclear reactors located at government-owned facilities. Such systems fit the NRC definition of a prototype or R\&D reactor that is operated either as a part of a power-generation facility (for an electric utility system) or is operated in any other manner for the purpose of demonstrating technology suitability for a commercial application. This includes facilities where work is conducted to resolve technical uncertainty, provide proof of concept, and generate verifiable data that is later to be used to improve the state of reactor technology.

Under Section 202 of the Energy Reorganization Act of 1974 (i.e., Public Law 93-438), NRC also has licensing authority for demonstration liquid-metal fast breeder and other types of demonstration nuclear reactors. NRC does not have regulatory authority over reactors located at government-owned facilities that are used purely for purposes of collecting research data, materials testing, fuels testing, or reactors that are otherwise dedicated to national military defense systems.

The Nuclear Energy Institute (NEI) recently released a roadmap concerning the possible deployment of microreactors at DoD facilities [6]. The recommendations contained in the NEI report assume NRC will license and regulate domestic microreactor installations and operations that include stateside DoD facilities. Regulations associated with NRC licenses, certifications, and approvals are contained in 10 CFR 50 and 52 and are supported by extensive compliance-guidance documentation. A summary on how NRC processes are utilized in nuclear plant licensing can be found in NUREG/BR-0298, "Nuclear Power Plant Licensing Process" [7]. Another easy-to-read informational resource that includes NRC's environmental review processes for nuclear power plant siting and construction is NUREG/BR-0468, "Frequently Asked Questions About License Applications for New Nuclear Power Reactors" [8].

\subsubsection{Department of Energy}

Statutory authority governing the cooperation between the NRC and DOE is well established. The DOE mission emphasizes performance of critical R\&D that supports nuclear-science advancement and safety. DOE also has authority to self-license research and test reactors at DOE-owned sites for purposes of collecting data and information in basic research and materials and fuels testing.

DOE test and research reactors can be authorized under 10 CFR 830, Nuclear Safety Management, using a safety analysis that is prepared using NRC regulatory guidance such as Regulatory Guide (RG) 1.70, "Standard Format and Content of Safety Analysis Reports for Nuclear Power Plants (LWR Edition)" [9]. Any reactor located on a DOE site that is operated for the purpose of demonstrating the 
suitability of a commercial application or producing energy, however, is to be licensed by the NRC. Note that DOE will be licensing a new test reactor, the Virtual Test Reactor, in the next decade. While this test reactor is not similar in design or function to microreactors, this effort will exercise DOE's nuclear-safety and licensing infrastructure.

While the AEA appears to permit DOE to authorize microreactors for DoD installations, it is likely that programmatic authority to license microreactors for defense installations would still need to be clarified by federal statue or through an executive order like the one that established Naval Reactors. Once the requisite authority is established, DOE might opt to license microreactors for remote domestic bases through the Office of Naval Reactors. It should be noted that Naval Reactors licensing of microreactors would require changes to the license-basis documents being used for naval nuclear propulsion because the design criteria are different for a stationary electric-power or steam-producing reactor. Alternatively, DOE could presumably establish a separate office on the basis that the missions of licensing naval reactors and microreactors are sufficiently different. Nonetheless, it is acknowledged that Naval Reactors has deep institutional expertise and long-term operational excellence in licensing small reactors from which the licensing of microreactors could benefit.

Barring a change in statue, DOE can authorize construction and operation of research and test reactors that are not operated to demonstrate design suitability for commercial applications or a power generation facility that is part of an electric-utility system. If such a facility was likely to be used as a developmental platform for forthcoming commercial power-reactor design, or if ownership of the facility is held by a private party, that facility would normally fall under NRC regulatory oversight, and an NRC license would be needed even though the facility is located on DOE property. DOE or DoD authorization would preclude commercial use of the reactor design, thereby making this option unattractive to target markets of suppliers.

There have been several instances of past DOE-NRC cooperation in nuclear projects where the NRC staff conduced reviews of safety cases and issues of licensability at a DOE-authorized reactor facility. The goal of such collaborations was to share technical support and feedback concerning technical safety at the DOE facility, rather than share regulatory-oversight responsibility. An example of such collaboration was the Fast Flux Test Facility (FFTF). The FFTF was a sodium-cooled test reactor built on the DOE's Hanford site. It was a DOE-regulated facility but used NRC and Advisory Committee on Reactor Safeguards (ACRS) to reevaluate the design prior to operation.

\subsubsection{Department of Defense}

General statutory authority does exist for the DoD to construct and operate a nuclear reactor that serves the military infrastructure. The AEA, as amended through 42 United States Code (USC) 2121, states that:

(b)(2) The President from time to time may authorize the Department of Defense
to manufacture, produce, or acquire any atomic weapon or utilization facility for
military purposes: Provided, however, that such authorization shall not extend to
the production of special nuclear material other than that incidental to the
operation of such utilization facilities

Furthermore, DoD does have experience in operating nuclear reactors, albeit much of that experience is decades old. The U.S. Army, Navy, and Air Force have each separately authorized and operated nuclear power plants in the past, with most of that experience starting in the 1950s and extending through the 1970 s.

Discussions within the industry have suggested that DoD may be a viable authorization and regulatory-oversight resource concerning certain microreactor technologies [3]. The Army still owns and is in the process of decommissioning nuclear reactors. The Navy owns and operates reactors on naval vessels, and while this branch of service still designs, licenses, and operates nuclear reactors for the 
nation's submarine and aircraft carrier fleet, those units are based on LWR technology used in mobile weapons-platform propulsion, neither of which address microreactor target applications. While legislation could expand existing DoD authority to create new programs that support microreactor utilization, statutory prohibitions exist against using DoD reactors in non-military applications.

DoD oversight authority could be a way to address ultra-mobile microreactor transport and operations using unirradiated or used fuel (also known as spent fuel with high radioactivity) in military design-basis threat (DBT) environments. Some key considerations in planning for military transport and operations options are illustrated in Figure 2 [10].

Unless there is complete DOE or DoD regulatory oversight throughout the entire chain of manufacture, deployment, utilization, and decommissioning, an NRC license would likely be required somewhere in the microreactor-utilization cycle. Public venues like roads, railroads, and airways that are used for reactor-module transport would also be subject to NRC regulatory analysis triggered by commercial transport over public thoroughfares. While there are examples of U.S. government organizations operating reactors nominally exempt from civilian licensing requirements, this option seems impractical given that microreactors are a solution to commercial energy supply needs and the limits imposed by a DOE/DoD authorization would act as a formidable barrier in attaining commercialization objectives.

Disadvantages embedded in legal DOE and DoD authorization and reactor usage constraints makes the non-NRC regulatory oversight option much less desirable for many aspiring suppliers. Furthermore, except for the DoD and DOE allowances, non-DoD entities (and their operations contractors) would likely be required to seek an NRC license in order to transfer or receive in interstate commerce, manufacture, produce, transfer, acquire, possess, use, import, or export utilization or production facilities for industrial or commercial purposes.

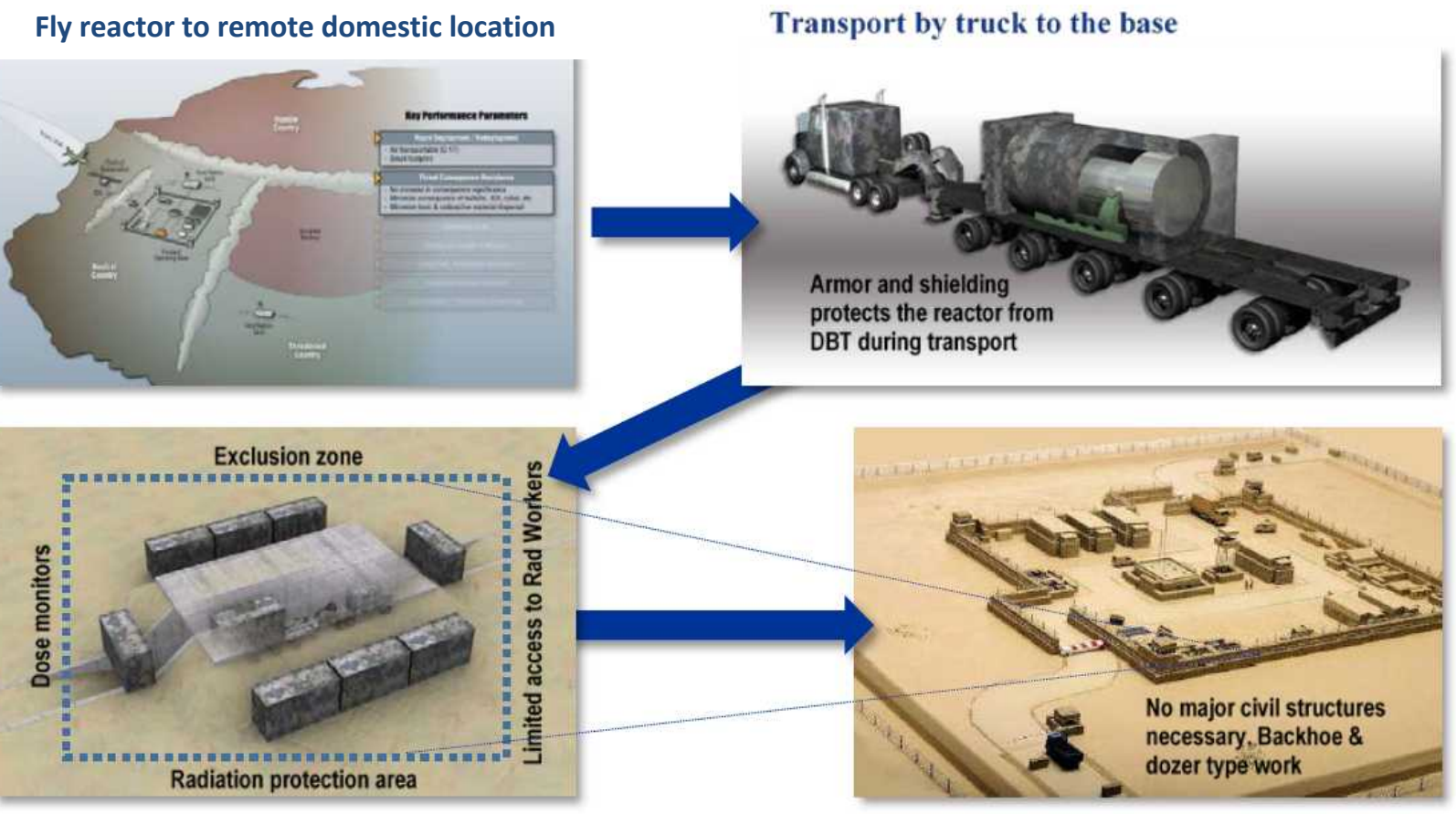

Protect by earth, barriers, and water jackets

Integrate into the base

Figure 2. Considerations in military microreactor applications. 


\subsection{State and Local}

State and local governments do not license commercial nuclear technology in the U.S. However, they do issue permits and allowances that may be required to support a plant at any given location. These authorities can vary substantially by locality and in scope of jurisdictional authority. However, state and local jurisdictions almost always include control of environmental media impacts (especially air and water resources) and socioeconomic factors that can influence the infrastructure near proposed sites.

State and local authorities also retain significant responsibilities in deciding and implementing appropriate protective actions for the public during nuclear-plant radiological emergencies. These authorities are responsible for notifying the public, taking protective actions like evacuation, sheltering in place, and distributing potassium iodide pills to minimize radioiodine uptakes. State and local officials generally base their emergency-action decisions on protective-action recommendations made by the nuclear power plant operator as well as their own radiological or health organizations. Federal regulators will also provide advice, guidance, and support to state and local government officials, but neither the nuclear power plant operator nor the NRC can order the surrounding public to take protective actions. [8]

\section{Recommendation:}

This report assumes NRC as the nominal licensing authority for microreactors within the boundaries of the U.S. However, this presumption is insufficient to address the unique needs of DoD military expeditionary deployments. Detailed analysis is needed to determine appropriate regulatory oversight and formal interagency understandings are recommended regarding appropriate oversight and licensing authorities for ultra-mobile, commercially operated microreactors serving DoD operations in domestic and foreign theaters of operation. The analysis must include determinations whether regulatory clarity is sufficient under the current legal framework or new legislation is needed.

\section{REGULATORY ISSUES}

\subsection{Microreactor-module Transportation}

\subsubsection{Fuel Loading at Reactor Manufacturing Facility}

Unlike conventional nuclear plants - the components of which are built at a manufacturing facility but assembled at the plant site - nearly all a microreactor unit may be built and assembled at the reactormanufacturing facility and then shipped to the desired site. This means that microreactor fuel will need to be shipped to the plant-manufacturing facility and loaded into the reactor at this facility. Shipping the completely assembled microreactor will then involve having to meet NRC and DOT regulations for shipment of nuclear material. This presents a challenge since no fuel shipping containers have been designed to accommodate an entire reactor plant.

6.1.1.1 Scope of Current Regulations The primary regulatory authorities governing the transport of nuclear (fresh and spent) fuel in the U.S. are the DOT, as authorized for individual transportation activities, and the NRC:

- Packaging: 49 CFR 173, subparts A, B, and I

- Security plans: 49 CFR 172, subpart I

- Rail: 49 CFR 174, subparts A through D and K

- $\quad$ Air: 49 CFR 175

- Vessel: 49 CFR 176, subparts A through F and M

- Public Highway: 49 CFR 177 and 390-397 
- Package design criteria: NRC [10 CFR 71]

DOT regulates shippers of hazardous materials, including radioactive material, and oversees vehicle safety, routing, shipping papers, emergency response, and shipper training. The NRC approves the design, fabrication, use, and maintenance of shipping containers for the most-hazardous radioactive materials, including spent nuclear fuel, and regulates the physical protection of commercial spent fuel in transit against hostile acts. In addition, the NRC requires [10 CFR 71.5] radioactive materials shipments to comply with DOT's safety regulations for transporting hazardous materials [2].

The type of packaging to be used during transport is determined by the activity, type, and form of the material to be shipped. Depending on these factors, radioactive material is currently shipped in one of three types of containers.

1. Industrial packaging. Materials that present little hazard from radiation exposure due to their low level of radioactivity are shipped in industrial packages. These are known as strong, tight containers. This type of container will retain and protect the contents during normal transportation activities. Slightly contaminated clothing, laboratory samples, and smoke detectors are examples of materials that may be shipped in industrial packages.

2. Type A packaging. Radioactive materials with higher specific-activity levels are shipped in Type A packages. This class of packages must demonstrate an ability to withstand a series of tests without releasing contents. Regulations require that the package protect its contents and maintain sufficient shielding under conditions normally encountered during transportation. Typically, Type A packages are used to transport items like radiopharmaceuticals (i.e., radioactive materials for medical use) and certain regulatory-qualified industrial products.

3. Type B Packaging. Radioactive materials that exceed the limits of Type A package requirements must be shipped in Type B packages. Shippers use this type of package to transport materials that would present a significant radiation hazard to the public or the environment if there were a major release. For this reason, a Type B package design must not only demonstrate its ability to withstand tests simulating normal shipping conditions but must also withstand severe accident conditions without releasing contents. Type B packages are used to transport materials with high levels of radioactivity, such as spent fuel from nuclear power plants. These large, heavy packages provide shielding against the radiation.

Generally, DOT packaging regulations apply to Industrial and Type A packaging whereas NRC regulations apply to Type A fissile-materials packaging and Type B packaging. Industrial and Type A non-fissile packages are designed to resist the stresses of routine transportation and are not certified to maintain their integrity during accidents. Type B packages are designed to maintain their integrity in severe accidents. Refer to Section 6.2 for more discussion about transport of spent microreactor fuel.

A general license is issued to any licensee to transport fissile material, or to deliver fissile material to a carrier for transport if the material is shipped in accordance with 10 CFR 71.22. The fissile material need not be contained in a package which meets the standards of Subparts E and F of this part; however, the material must be contained in a Type A package. The Type A package must also meet the DOT requirements of 49 CFR 173.417(a).

External radiation limits for all types of packages are found in 10 CFR 71.47 (NRC) and 49 CFR 173.441 (DOT). Any package of radioactive materials offered for transportation must be designed and prepared for shipment so that the radiation level does not exceed $200 \mathrm{mrem} / \mathrm{h}(2 \mathrm{mSv} / \mathrm{h})$ at any point on the external surface of the package and that the transport index does not exceed 10. If a package exceeds 
this radiation limit, it must be transported by exclusive use shipment only, and the following conditions must be met during transportation:

- Radiation levels on any point of the external surface of the package are limited to $1000 \mathrm{mrem} / \mathrm{h}$ (10 $\mathrm{mSv} / \mathrm{h})$

- The shipment is made in a closed transport vehicle

- The package is secured within the vehicle so that its position remains fixed during transportation

- There are no loading or unloading operations between the beginning and end of the transportation.

There are additional external radiation limits associated with the outer surface of the vehicle (200 $\mathrm{mrem} / \mathrm{h})$, any point 2 meters from the outer lateral surfaces of the vehicle $(10 \mathrm{mrem} / \mathrm{h})$, and any occupied space $(2 \mathrm{mrem} / \mathrm{h})$ unless a private carrier is used and personnel are using radiation dosimetry.

6.1.1.2 Type A Package Criticality Evaluation. NRC regulations 10 CFR 71.55 require that Type A packages used for fissile-material shipment must be designed and constructed, and their contents limited, such that they remain subcritical if water leaks into the containment systems. Therefore, a criticality evaluation must be performed before any package design can be certified for use in transporting HALEU. The criticality evaluation ensures that a single package remains subcritical under both normal conditions of transport and in hypothetical accident conditions. The evaluations consider:

- Fissile material in its most-reactive credible configuration consistent with the condition of the package and the chemical and physical form of the contents

- Water moderation to the most-reactive credible extent, including water in-leakage to the containment system as specified in $§ 71.55(\mathrm{~b})$

- Full water reflection on all sides of the containment system as specified in $\S 71.55(\mathrm{~b})(3)$, or reflection by the package materials, whichever results in the maximum reactivity.

Similar evaluations are performed for an array of packages under normal conditions of transport:

- The most-reactive configuration of the array (e.g., pitch, package orientation, and internal moderation) with nothing between the packages

- The most-reactive credible configuration of the packaging and its contents under normal conditions of transport. If the water-spray test has demonstrated that water would not leak into the package, water in-leakage need not be assumed, and

- Full water reflection on all sides of a finite array.

In addition, the review must ensure that the criticality evaluation demonstrates an array of packages remain subcritical under hypothetical accident conditions. The evaluation should consider:

- The most-reactive configuration of the array (e.g., pitch, package orientation, and internal moderation)

- Optimum interspersed hydrogenous moderation

- The most reactive-credible configuration of the packaging and its contents under hypothetical accident conditions, including in-leakage of water

- Full water reflection on all sides of a finite array.

The criticality analysis is a significant factor in the certification of HALEU transportation packages. Less benchmark data is available for enrichments above five percent; this indicates a need to rely on computer codes and greater uncertainty assumptions to help designers establish adequate margins to cover the lack of benchmark validation. Developing additional criticality-benchmark data at these higher enrichments would reduce such reliance. 
Benchmark experiments should have, to the maximum extent possible, the same materials, neutron spectra, and configuration as the package evaluations. Key package parameters that should be compared with those of the benchmark experiments include type of fissile material, enrichment, hydrogen/uranium ratio, poison, and configuration. In addition, the package application should address overall quality of benchmark experiments and uncertainties in experimental data (e.g., mass, density, dimensions). Enough benchmark experiments must be analyzed, and the results of these benchmark calculations are used to determine an appropriate bias for the package calculations. Guidance on benchmarking of nuclear criticality codes is provided in NUREG/CR-6361 [11]. NUREG 1609, "Standard Review Plan for Transportation Packages for Radioactive Material," provides guidance for reviewing radioactive material transport package applications.

To facilitate the development of technology using HALEU, industry and regulators need to develop criticality benchmark data that allow the safe and effective use of HALEU fuels. As a part of this effort, it is important to identify the range of material forms that will potentially be needed as it will impact experiments.

6.1.1.3 Gaps in the Current Regulations. As noted above, the current LWR fleet use LEU fuel that is transported (prior to irradiation) using Type A packaging. The main goal of this packaging is to protect transportation workers and the general public from radiation exposure and to provide nuclear criticality safety under normal and severe conditions. For fresh fuel, the packaging may be constructed of steel boxes placed within wooden boxes or in a cradle assembly that holds fuels firmly to a rigid beam called a "strongback" [12].

For all three of the microreactor deployment scenarios discussed in Subsection 4.4, fresh HALEU fuel can be assumed to be transported to the microreactor factory and then from the microreactor facility to the site (as a fully loaded reactor core). To transfer fresh HALEU fuel via these scenarios, industry will need to develop and qualify new Type A packaging for fissile material. Current Congressional instructions direct DOE to complete this task through Senate Bill 903, "Nuclear Energy Leadership Act" (NELA).

SB 903 language that addresses transportation includes the following:

As soon as practicable after the date of enactment of this section, the Secretary shall establish a research, development, and demonstration program under which the Secretary shall provide grants, on a competitive basis, to establish the capability to transport high-assay, low enriched uranium.

The focus of the program under this subsection shall be to establish 1 or more HALEU transportation packages that can be certified by the Nuclear Regulatory Commission to transport high-assay, low-enriched uranium to the various facilities involved in producing or using nuclear fuel containing high-assay, low-enriched uranium, such as:

(A) Enrichment facilities;

(B) Fuel processing facilities;

(C) Fuel fabrication facilities; and

(D) Nuclear reactors.

Regardless of the outcome of this legislation, effort will be required on the part of DOE and the laboratory complex to plan and complete necessary activities leading to the certification of a new Type A packaging that can transport fresh HALEU fuel to microreactor-manufacturing facilities or construction site.

\section{Recommendation:}


Industry and NRC should review the existing Part 71 regulations to determine whether changes are required, or new guidance must be developed to address transport of HALEU fuel to a manufacturing facility and subsequent transport of a fully $\mathrm{HALEU}$-fueled reactor to a site.

Industry and DOE, in cooperation with the NRC, should develop the necessary criticality benchmark data, to allow efficient and cost-effective licensing of a new generation of $H A L E U$ fuel facilities and transportation packages. HALEU licensees will likely need this criticality benchmark data to achieve an efficient cost-effective design option.

\subsubsection{Physical Security During Transport}

6.1.2.1 Current Regulations. Performance objectives of physical protection systems during transit are described in $\$ 73.67$ (a) for Category II materials. Similar to fixed-facility physical-protection requirements, physical-protection requirements for material in transit are graded based on risk. Also, it should be noted that 10 CFR 73.24, "Prohibitions," requires NRC preapproval of shipment schedules for Category II transport. (NEI 01/2018)

Transportation of spent nuclear fuel and other high-activity shipments also require physical protection with key features including:

1. Use of NRC-certified, structurally rugged shipment overpacks and canisters. Fuel within canisters are to be dense and in solid form, not readily dispersible as respirable particles.

2. Advanced planning and coordination with local law enforcement along approved routes.

3. Protection of information about transfer schedules.

4. Regular communication between transport units and control centers.

5. Armed escorts within heavily populated areas.

6. Vehicle immobility measures to protect against movement of a hijacked shipment before response forces arrive

6.1.2.2 Gaps in Regulations. The regulatory requirements for physical security of Category II special nuclear material (SNM) apply to HALEU fuel and are described in 10 CFR 73.67. However, until recent medical-isotope facility applicants, no U.S. facilities have been licensed to possess special nuclear material of moderate strategic significance for several decades. Over time, the perceived threat environment has changed, however; as a result, protective measures for Category II SNM will likely be reevaluated for current perceived threats. (NEI 01/2018)

\section{Recommendation:}

NRC should evaluate the adequacy of existing Part 73 regulations to ensure that they adequately and clearly address physical security of HALEU that is transported both to a manufacturing facility and from a manufacturing facility to a site.

\subsection{Transport of Operated Microreactor Modules to New Operational Sites}

Spent nuclear fuel generally consists of highly radioactive fuel bundled into design-specific fuel assemblies. After it is removed from a reactor, spent fuel from LWRs is required to be stored on site to cool for at least one year after being used as a source of energy in a power reactor. If transported, spent fuel must be placed in containers that shield and contain the radioactivity and dissipate generated residual heat. 
Table 1 is a listing of Type B transportation casks that have been licensed by the NRC. The HI-STAR 100 cask has one of the largest capacities but is still limited to 24 pressurized water reactor (PWR) fuel assemblies. Also note that this large transport cask is limited to rail transportation. Therefore, it will be important to ensure that any Type B cask developed for use by a microreactor does not exceed the size/weight limitation to utilize truck transportation. Otherwise, potential sites will be limited to ones that have adequate rail service.

Table 1. Transportation casks currently licensed by NRC.

\begin{tabular}{|c|c|c|c|c|}
\hline Cask & Package ID & Canister & $\begin{array}{c}\text { Contents (Number of } \\
\text { assemblies) }\end{array}$ & Type \\
\hline IF-300 & USA/9001/B( )F & No & 7 PWR, 17 BWR & Rail \\
\hline NLI-1/2 & USA/9010/B( )F & $\mathrm{No}$ & 1 PWR, 2 BWR & Truck \\
\hline TN-8 & USA/9015/B( )F & $\mathrm{No}$ & 3 PWR & Overweight $^{\mathrm{a}}$ \\
\hline TN-9 & USA/9016/B( )F & No & 7 BWR & Overweight $^{\mathrm{a}}$ \\
\hline NLI-10/24 & USA/9023/B( )F & No & 10 PWR, 24 BWR & Rail \\
\hline NAC-LWT & USA/9225/B(U)F-96 & No & 1 PWR, 2 BWR & Truck \\
\hline GA-4 & USA/9226/B(U)F-85 & No & 4 PWR & Truck \\
\hline NAC-STC & USA/9235/B(U)F-85 & Both & 26 PWR & Rail \\
\hline NUHOMS®-MP 187 & USA/9255/B(U)F-85 & Yes & 24 PWR & Rail \\
\hline HI-STAR 100 & USA/9261/B(U)F-85 & Yes & 24 PWR, 68 BWR & Rail \\
\hline NAC-UMS & USA/9270/B(U)F-85 & Yes & 24 PWR, 56 BWR & Rail \\
\hline TS125 & USA/9276/B(U)F-85 & Yes & $21 \mathrm{PWR}, 64 \mathrm{BWR}$ & Rail \\
\hline TN-68 & USA/9293/B(U)F-85 & No & $68 \mathrm{BWR}$ & Rail \\
\hline NUHOMS®-MP 197 & USA/9302/B(U)F-85 & Yes & $61 \mathrm{BWR}$ & Rail \\
\hline
\end{tabular}

\subsubsection{Site-to-Site Microreactor Transport}

One of the more challenging aspects of microreactor transportation is related to module transport from factory to multiple use sites for commercial purposes and module transport to a permanent or transient site, with eventual return to the factory. Both scenarios involve moving a previously operated microreactor from one site to a different location without removing the partially spent fuel prior to mobilization. In these cases, the fuel must remain contained in the microreactor module to facilitate movement to another location.

6.2.1.1 Current Regulations. NRC regulations in 10 CFR Part 71 establish requirements for packaging, preparation for shipment, and transportation of licensed material, including packaging and shipping procedures for fissile material. Currently, most spent fuel in the U.S. is stored on-site, and very little transportation of spent commercial power reactor fuel takes place. The spent-fuel transportation casks that are available today are rated for heat load, which often determines the cooling time needed for the fuel to be transported. Shielding or other considerations may also drive required cooling time.

A spent-fuel transport package must be able to withstand hot and cold environments, changes in pressure, vibration, water spray, impact, puncture and compression associated with normal conditions. To show that it can withstand accident conditions, a package must also pass impact, puncture, fire and water immersion tests (Figure 3). Transportation packages must survive these tests in sequence, including a 30-foot drop onto a rigid surface, a 40-inch drop onto a fixed 6-inch diameter steel cylinder (to test package resistance to punctures), followed by a fully-engulfing fire of $1,475^{\circ} \mathrm{F}$ for 30 minutes. The final tests in the sequence include immersion in 3 feet of water and a nonsequential immersion in 50 feet of water for 1 hour. These are very severe tests and equate to the package hitting a concrete highway overpass at high speed and involvement in a severe and long-lasting fire. The test sequence encompasses 
more than $99 \%$ of all vehicle accidents. The NRC reviews each package design to confirm that it meets the required conditions. The NRC must issue an approval certificate before a package can be used to transport spent fuel [13].

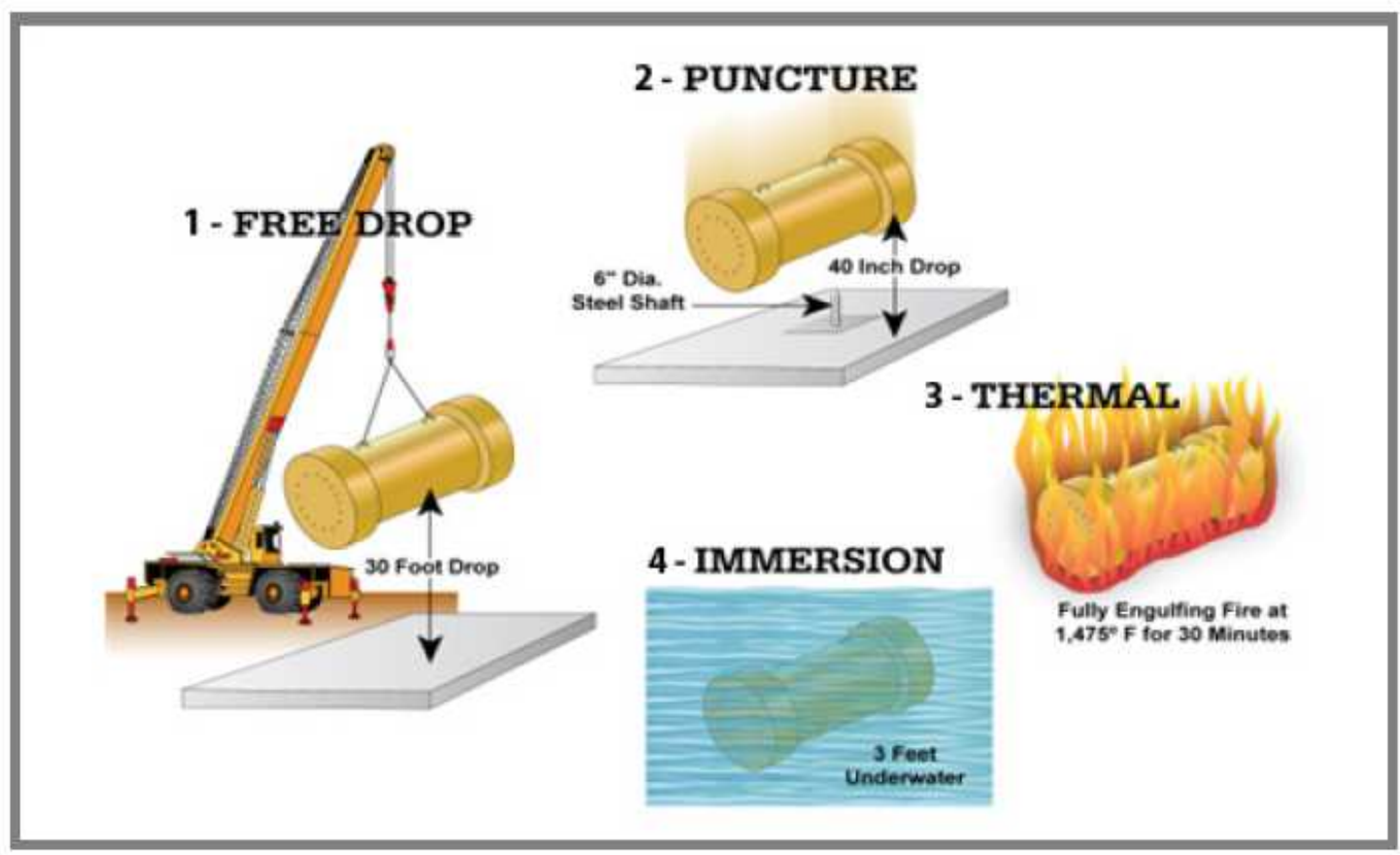

Figure 3. Type B package certification testing.

Testing is the responsibility of the transportation-cask designer. Tests are performed on a package design, either physically, using a full-scale prototype or a sub-scale test unit, or via computational modeling. A package designer may create computer models to evaluate the performance of a package design or components of the package design, build full-size or scale-model packages for physical testing, or incorporate references to previous satisfactory demonstrations of a similar nature. In practice, the safety analysis performed for Type B packages often incorporates a combination of physical testing, computer modeling, and engineering evaluation. The safety analysis report contains information on the package design's performance in the tests and an evaluation against the acceptance criteria in 10 CFR Part 71 . The safety analysis report is used to apply for package certification. During the certification process, the NRC reviews the safety analysis report to ensure that the package design meets all criteria specified in 10 CFR 71; further details can be found in NUREG-2125, "Spent Fuel Transportation Risk Assessment-Final Report." Once all requirements are met, the NRC issues a certificate of compliance for the cask design.

6.2.1.2 Gaps in the Regulations. Note that 10 CFR 71.4 defines spent fuel as "fuel that has been withdrawn from a nuclear reactor following irradiation, has undergone at least one year's decay since being used as a source of energy in a power reactor, and has not been chemically separated into its constituent elements by reprocessing." The complication is that microreactor used fuel will not be withdrawn from the reactor prior to the reactor's being moved or relocated, nor will it have undergone one year of decay prior to transport.

The DOT/NRC regulations regarding the transport of radioactive material will apply to transport of previously operated microreactors. This will necessitate the use of a qualified Type B package to get the microreactor module from the first operating location to a second. Given the need for a qualified Type B transport package, the following three possible options may exist: 
1. Enclose the microreactor in an existing qualified Type B package. Using an existing qualified Type B package will impose severe restrictions on the size of the microreactor core/vessel structure. For example, the Holtec HI-STAR 100 cask (designed for rail transport) has an interior cavity that is approximately 69 inches in diameter and 191 inches long. Any microreactor vessel inserted into this cask would need to have external systems detached and control rods fixed in-place (with the possible addition of a core neutron absorber) to ensure adequate shutdown margins during transport. While the Holtec cask is designed for a rail car, other Type B packages designed for truck transport have even smaller cavities and therefore place greater restriction on microreactor dimensions.

Additional considerations include the fuel type and enrichment that are used in the microreactor design. Most developers have identified the need for a HALEU supply. However, existing qualified Type B packages are limited to the transport of fuel that is enriched to a maximum of $5 \%$. Therefore, existing qualified packaging is not available for designs that use HALEU.

Decay-heat removal is another concern to be addressed. Moving a recently shutdown microreactor to a new location must contend and deal with significant amounts of decay heat. Each Type B package has a specified thermal limit that must be met, and this decay heat may challenge that specification.

2. Develop and qualify a new Type B package that is large enough to house a microreactor. The need for development and qualification of a new transport package that can be used for HALEU has been identified by NEI and other organizations. As part of this effort to accommodate HALEU, it would be reasonable to develop a new Type $B$ package that could contain a range of microreactor designs without requiring fuel removal prior to transport. This would require careful consideration of proposed microreactor configurations to establish necessary cavity dimensions for packaging as well as methods for residual-heat removal and fail-safe assurance of criticality control. Additional restrictions would apply if the packaging requires railcar-sized transport. If so, proposed microreactor sites would need to be accessible by rail. Any Type B package that is developed would be subject to the qualification-testing process outlined in Subsection 6.3.

New Type B packages will have a specified thermal limit. For a new design, this thermal limit should be based on the maximum decay-heat output expected for the microreactor designs considered.

3. Qualify the microreactor itself as a Type B package (with no additional enclosure). This option means the microreactor core and vessel structure would serve as the Type B package. This would necessitate considerable design in order to provide the reactor vessel with the strength and shielding necessary to meet transportation regulations and to pass the Type B package-qualification test process outlined in Subsection 6.3. As with the other options, size and weight are a concern if the microreactor module is to be transported via truck or rail.

In addition, the issue of decay-heat removal during transport needs to be addressed in microreactor design. It can be assumed that any parameter incorporated into a reactor vessel for purposes of addressing transportation requirements will, in turn, influence the reactor-vessel performance characteristics during normal and off-normal operations. Sophisticated new assessment techniques will be required to evaluate the effect and consequences of these dual-mode performance goals on the reactor vessel.

Maintaining subcriticality during transport will be a major safety consideration during certification. The approach used to maintain microreactor subcriticality must be sufficiently robust so as to 
withstand the full Type B qualification-test process. Considerable analysis and testing will be needed to create a microreactor-vessel design that is configured to meet its intended energy-generation application while, at the same time, being able to survive a 30 foot drop at the most restrictive angle and the other Type B package accident-testing requirements. These required tests are focused on ensuring the Type B package (or in this case the microreactor vessel) can still retain fission products after experiencing potential transportation-related accidents. However, the unique situation presented by moving intact microreactors (including fuel) from one location to another would suggest that additional safety analysis should be completed to determine whether external transportation events have an impact on microreactor core internals, reactivity-control systems, shielding, or heat-removal capabilities. These events could be identified and analyzed using a process similar to that described in NEI 18-04, "Risk-Informed Performance-Based Guidance for Non-Light Water Reactor Licensing Basis Development" [5].

Consideration must also be given to the design criteria applied during development of the microreactor design during transport mode. Existing design criteria, such as those found in 10 CFR 50, Appendix A, or Regulatory Guide 1.232, "Guidance for Developing Principle Design Criteria for Non-Light-Water Reactors," assume the reactor will remain stationary once construction is complete. However, transportation operations will create additional design loads for the vessel and core that necessitate additional design considerations. Examples may include advanced-reactor design criteria (ARDC-10 - Reactor Design), ARDC-15 (Reactor Coolant System Design), and others related to reactivity control and fluid systems.

\section{Recommendation:}

Initiate efforts to determine the best approach in developing and qualifying a new Type B package that accommodates transport of microreactors to different sites after initial criticality while retaining the fuel within the reactor vessel. This effort should determine if a Type B over-pack of the microreactor is possible (while providing necessary shielding and decay-heat removal capabilities) or if it is feasible to use the microreactor vessel itself as a Type B package. These two options should be compared to removing the fuel (on-site) prior to relocating the microreactor to its new site location and having the used fuel transported to the new location using existing Type B packaging. These evaluations will require significant engagement and coordination with microreactor stakeholders, Type B cask vendors, DOE, and NRC.

Identify changes in Part 71 regulations needed to address the transport of previously operated microreactors (including the used fuel). As an interim measure while new regulations are being developed, guidance should be developed that would specify the necessary criteria a microreactor applicant would need to address in order to obtain an exemption from applicable requirements.

\subsubsection{Reactor Startup and Restart Testing Requirements for Site-specific ITAAC}

6.2.2.1 Current Regulations. A combined operating license (COL) enables licensees to construct a plant and operate it once construction is complete provided certain standards identified in the COL are satisfied. These standards are called Inspections, Tests, Analyses, and Acceptance Criteria (ITAACs). ITAACs are typically derived from one of two sources of information. The majority of ITAAC come from the design certification for a reactor technology used at the plant. Subpart B of 10 CFR 52 defines regulatory requirements for nuclear design-certification applications and is certified through rulemaking. The remaining ITAACs are site related and submitted to NRC in the licensee's COL or early site-permit application.

The following is required by 10 CFR 52.97(b): 
(b) The Commission shall identify within the combined license the inspections, tests, and analyses, including those applicable to emergency planning, that the licensee shall perform, and the acceptance criteria that, if met, are necessary and sufficient to provide reasonable assurance that the facility has been constructed and will be operated in conformity with the license, the provisions of the Act, and the Commission's rules and regulations.

ITAACs provide licensees and the NRC with reasonable assurance that the nuclear facility has been constructed and will operate in conformance with the combined license, the provisions of the AEA (as amended), and applicable rules, regulations and requirements. While 10 CFR 50 addresses ITAAC completion in the context of a single operating license, 10 CFR 52 addresses ITAAC in a more independent manner that seemingly fits with the deployment scenarios anticipated for microreactors. On this basis, the remaining ITAAC discussion follows 10 CFR 52 requirements.

Design certification ITAACs are developed by technology suppliers as a basis to assure that, if the inspections, tests, and analyses are performed, and the acceptance criteria met, the facility has conformed to construction specifications and will be operated according to their design certification and operational conditions.

During construction, the licensee is responsible for performing all ITAACs and ensuring acceptance criteria are met. Throughout construction, NRC inspectors perform inspections at the plant site to confirm licensee findings. Furthermore, for every completed ITAAC, the licensee must submit to NRC an ITAAC Closure Notification (ICN) as required under 10 CFR 52.99(c)(1). The staff then reviews each ICN to verify the ITAAC was successfully completed and periodically publishes a record of these reviews in the Federal Register.

All ITAACs in a contemporary design certification must be verified as complete before a fuel load is authorized by the NRC. Upon successful completion of all ITAACs and staff verification that all acceptance criteria have been met, a recommendation will be made to the Commission that all acceptance criteria be declared as met. 10 CFR $52.103(\mathrm{~g})$ requires that the licensee shall not operate the facility until the Commission makes such a finding. If the combined license is for a modular design, each reactor module may require a separate finding as construction proceeds.

6.2.2.2 Gaps in the Regulations. Current preoperational and startup requirement validation processes are lengthy and not structured to address a fully constructed nuclear plant built off-site and shipped as a unit (perhaps as a sealed package) to a user location. Current ITAAC regulations do not address scenarios that involve transport of a previously operated microreactor module to a new site, or for completing ITAAC after fuel has already been loaded. New regulations will be necessary to determine to what extent previously completed ITAACs need to be repeated or new ITAACs needed to address issues associated with microreactor material condition following transport. Since fueled module transport is a new area of reactor operations concern, ITAAC may be required to ensure that transportation activities did not cause configuration changes or component damage that influence safe operation.

\section{Recommendation:}

Evaluate existing preoperational testing requirements and determine if changes or new guidance is needed to address microreactor siting and operations. Consider the following:

- Fuel loading/unloading of modules at a factory along with field inspections and servicing

- Preparation for and module transport operations (fueled and unfueled) between the manufacturing facility and user sites

- The scope of ITAAC for operated and fueled microreactors being transported to a new site

- In-service inspection requirements during all phases of module utilization 
As an interim measure, guidance should be developed that specify necessary criteria a microreactor applicant must address in order to obtain exemption from inappropriate requirements.

\subsection{Siting Independence}

A versatile and robust means for site characterization and permitting is needed to support transient and semi-permanent microreactor field installations. Modifying the way sites are identified, qualified, and subsequently managed in relation to the risks presented by and to the operating plant is an important issue particularly if increased siting independence is a deployment objective. Topics discussed in this subsection include site characterization, environmental assessments, scalable emergency preparedness, establishing design-safety criteria compatible with reactor-module mobility, grid-reliability concerns, and collocation with industry.

\subsubsection{Environmental Report}

A microreactor site will require proximity to the target customer, energy-transmission capabilities, and accessibility and serviceability with respect to module transport, installation, and operations. Multiple sites may be proposed along with a preferred site to allow applicants and regulators opportunities to consider potential risk and impact trade-offs associated with sites. An approach to conducting an initial site screening amongst multiple advanced reactor technology sites (using existing NRC siting criteria) was developed by the Idaho National Laboratory (INL) [14].

6.3.1.1 Current Regulations. Site evaluation methodologies and site qualification guidance for large nuclear power stations are available for use in NRC licensing. Environmental regulatory reviews are based on information collected according to NRC RG 4.2, "Preparation of Environmental Reports for Nuclear Power Stations" [15]. The guidance is structured to provide for in-depth assessments of potential site impacts and offers detailed risk-analysis information concerning plant construction, operations, and decommissioning. Criteria used to determine site suitability is presented in in RG 4.7, "General Site Suitability Criteria for Nuclear Power Stations" [16].

During the licensing process, the applicant is required to supply NRC an environmental report (ER) which contains vast amounts of site-specific information as identified in RG 4.2 guidance. Major topics subject to review include:

- Presence and role of existing infrastructure in supporting the plant

- Site geology, seismology, and soil geotechnical properties

- Hydrology and water use

- Nearby hazardous activities that could affect plant safety

- Extreme weather considerations

- Dispersion of radiological releases during plant-accident conditions

- Emergency planning for the plant and surrounding area

- Impacts on area populations

- Various societal effects

- Impacts on terrestrial and aquatic ecology

- Land use for transmission corridors and transportation routes

- Historic, archeological, and cultural resources

- Land availability to support safe plant operations 
- Factors affecting plant constructability

- Features that could affect security measures and security plans.

6.3.1.2 Gaps in the Regulations. It should be noted that the aforementioned site characterization topics are of concern primarily due to the potential for interaction with activities associated with large stationary LWR power plants at a permanent location; virtually no consideration or allowance is given to RG 4.2 topics concerning the transport, installation, operation, and changeout of mobile nuclear modules at impermanent locations.

If technology suppliers succeed in demonstrating significant increase in inherent and passive design safety, the risk profiles associated with microreactors at a site will likely be much different from that of a typical large LWR plant. Normal and accident radiological source terms for very small machines should translate into much less potential for a major dose consequence. Increases in defense-in-depth safety could influence many site factors and lessen plant sensitivity to the onset of adverse site conditions. Examples of this shift include the need for site meteorological monitoring and topographical characterization and their influence in understanding potential radiological-plume dispersion patterns during accident events. Land availability and construction impact analysis may be an inconsequential concern for highly portable units that impose a minimal operating footprint. A significant change in potential plant-site risk could translate into commensurate changes in site characterization requirements with reductions in RG 4.2 characterization burdens being a principle reward for increased design safety.

Reducing the scope and level of detail associated with the RG 4.2 environmental report will also be a function of individual microreactor design. Local surface water impact evaluations may be negligible for designs that do not rely on water for core cooling but remain a concern for designs that depend on water for residual core heat removal. Highly portable designs might rely on rapid relocation capabilities to mitigate area surface hydrological risks while more permanent installations must consider and plan for such risks in a different manner. Furthermore, since risks accumulate over time, very short-term installations may merit a different site assessment regime then do longer-term use site.

Updates to RG 4.2 and other NRC environmental review guidance to reflect anticipated microreactor safety performance must be founded on a demonstrated understanding of associated safety basis and emergency-response capabilities for that technology. Attempting to amend NRC siting guidance without first understanding the underlying microreactor safety approach will likely not succeed in yielding meaningful regulatory change from current requirements. Similarly, while it might be easier to modify existing environmental review guidance to address permanent or semi-permanent microreactor installations in well-characterized locations, modifying existing siting protocols and acceptance criteria will probably be insufficient to address the needs of ultramobile module transport or transient installations at impermanent locations with little available site characterization information.

\section{Recommendation:}

If suppliers achieve substantive gains in intrinsic and inherent microreactor design safety, it is recommended that new site-characterization, qualification, and permitting guidance be developed that adequately and meaningfully address actual siting risk factors that are associated with the microreactor safety-case. The elements to be considered in the guidance include:

1. Create a "standard" microreactor safety basis against which all future siting regulatory reviews and acceptance can be benchmarked; include provisions that allow reviews of unique design features such as ultramobile modules at very short-term user installation.

2. Compare existing site characterization requirements against the standard microreactor safety case (established above) to identify which requirements are relevant and important in 
microreactor site safety; less important items topics would be candidate for reduced levels of regulatory review.

3. Some site characterization topics may remain a regulatory concern but need modification to improve workability. Gaps in important siting parameter (such as mobilization/demobilization of portable units at a site) may require new guidance.

Appendix $A$ of this report contains a proposal whereby a site-permitting process could be established using a permit-by-rule (PBR) authorization philosophy. Such a program could be established as an option under the NRC early site permit (ESP) program.

\subsubsection{Licensing Design Requirements}

6.3.2.1 Current Regulations. Licensing requirements contained in 10 CFR 50 and 10 CFR 52 include an obligation for applicants to establish principle design criteria (PDCs) as a minimum commitment to design safety. These PDCs are derived from 10 CFR 50, Appendix A, "General Design Criteria For Nuclear Power Plants," with case-by-case exceptions allowed to individual criteria. Appendix A General Design Criteria (GDCs) were written expressly to establish minimum requirements for LWR PDCs and, as stated in the introduction to Appendix A of Part 50,

The General Design Criteria are also considered to be generally applicable to other types of nuclear power units and are intended to provide guidance in establishing the principal design criteria for such other units.

All production and utilization facilities licensed under 10 CFR 50 are required to provide PDCs in a preliminary safety-analysis report that supports a construction-permit application as described in 10 CFR 50.34(a)(3).

6.3.2.2 Gaps in Regulations. Until recently, developing non-LWR PDCs was uncertain due to the LWR-centric nature of GDC descriptions and requirements. In response, NRC published RG 1.232, "Guidance for Developing Principal Design Criteria for Non-Light-Water Reactors" [17] to help interpret 10 CFR 50, Appendix A requirements for non-LWR designs. It should be noted, however, that while the ARDC guidance contained in RG 1.232 was intended to broadly address all non-LWR designs for which information was available at that time, this guidance does not consider microreactors as a distinctive technology class or prescribe any requirement uniquely appropriate to very small and mobile machines.

Microreactor PDCs will need to be established to ensure necessary design, fabrication, construction, testing, and performance requirements are attained in plant structures, systems, and components (SSCs) important to safety. In other words, any SSC that contributes a reasonable assurance that the nuclear plant will be operated without undue risk to the public must demonstrate compliance with applicable PDCs as derived from GDCs or ARDCs. It is therefore essential that microreactor suppliers evaluate PDC requirements driven by available GDC or ARDC guidance and ensure a safety design basis is developed befitting established regulatory expectations. Weakness or inconsistencies between a design and applicable design criteria will result in soliciting exceptions to the guidance from NRC or changes in the design to match requirements.

Establishing correct criteria against which PDCs are to be benchmarked is an important early concern in microreactor technology licensing. It is highly unlikely that existing design criteria and guidance are sufficiently clear or even applicable to effectively address the new mobility and transportation features expected in most microreactor designs. This concern is particularly evident concerning the transport of fully fueled modules - an operational circumstance never envisioned during the formulation of current GDC and ARDC guidance. 
An important example of a potential gap in existing design criteria involves core heat management and maintaining access to the ultimate heat sink during all modes of unit transport, staging and storage. Fueled reactor module transport is a new area of design safety that will require development of PDCs produced under relevant guidance. Extensive test information will be needed to stabilize and validate design criteria content in this area and demonstrate those criteria as appropriate to ensure safety and redundancy.

\section{Recommendation:}

Existing plant design criteria should be evaluated for applicability to microreactor technologies and determine whether new criteria are necessary to address unique deployment scenarios such as fueled module transport. Guidance should be developed that specifies the criteria a microreactor applicant must address in order to obtain exemption from currently applicable (but possibly inappropriate) design criteria requirements.

\subsubsection{Environmental Impact Assessment}

6.3.3.1 Current Regulations. NRC environmental-impact assessment requirements are derived from the AEA and subsequent implementing regulations. These regulations also reflect NRC's interpretation and implementation of the National Environmental Policy Act of 1969, 42 USC 4321 et seq. (NEPA) and the White House Council on Environmental Quality' s (CEQ' s) implementing regulations at 40 CFR 1500-1508.

NRC uses 10 CFR 51, "Environmental Protection Regulations for Domestic Licensing and Related Regulatory Functions," to implement NEPA and 10 CFR 51.20(b). These regulations mandate preparation of environmental impact statements (EISs) covering the construction and operation of nuclear reactors. While both NEPA and CEQ regulations afford significant latitude in the mechanisms a federal agency uses to fulfill environmental review obligations, NRC has historically examined these impacts on a site-specific basis.

The NEPA process was created to ensure well-informed decision making in major federal actions. The Commission has determined that licensing a nuclear facility constitutes a major federal action, thereby indicating an EIS is to be prepared for every newly issued nuclear-facility license. NEPA does not guarantee any particular outcome or that a superior environmental alternative be selected in agency decisions but, rather, that decision be fully informed concerning associated environmental factors.

Because the Commission has determined that issuing a permit to construct a nuclear power reactor shall be covered by an EIS, it can be presumed that each future NRC microreactor site permitting action would be subject to an EIS analysis. At this time, the staff has indicated intentions to review the status of this determination and may release Interim Staff Guidance (ISG) on the topic at some future time.

Until then, NRC as the lead federal agency is responsible for completing the EIS prior to issuing a license to site, construct, and operate a reactor. An environmental report for each individual site is required of license applicants and submitted to the NRC as part of the license-application process. This report is used by the staff as the primary informational resource in preparing the EIS.

General requirements for an NRC environmental report are contained in 10 CFR 51.45. Paragraph c of this requirement states, in part, that:

(c) Analysis. The environmental report must include an analysis that considers and balances the environmental effects of the proposed action, the environmental impacts of alternatives to the proposed action, and alternatives available for reducing or avoiding adverse environmental effects. ...The environmental report must also contain an analysis of the cumulative impacts of the activities to be authorized by the limited work authorization, construction permit, or combined license in light of the preconstruction impacts described in the environmental 
report. ... The analyses for environmental reports shall, to the fullest extent practicable, quantify the various factors considered. To the extent that there are important qualitative considerations or factors that cannot be quantified, those considerations or factors shall be discussed in qualitative terms. The environmental report should contain sufficient data to aid the Commission in its development of an independent analysis.

The environmental review typically required by the Commission includes analysis of:

- The need for power

- Socioeconomic impacts

- Transportation impacts

- Human-health issues associated with the proposed action

- Transmission lines and related human-health impacts

- Alternatives to the proposed action including the alternative to take no action

- Accident reviews and severe-accident mitigation alternatives

- Review of decommissioning actions.

6.3.3.2 Gaps in the Regulations. A site ER review by NRC typically takes 2 years and involves public hearings and the preparation of an EIS. At this time, ESP applications submitted to NRC by applicants in accordance with 10 CFR Part 52 trigger an environmental review in the form of an EIS. As such, the process now used by NRC in satisfying its NEPA obligation represents a significant potential impediment in streamlining the site review and approval for microreactors.

In a letter to the $\mathrm{NRC}$ regarding advanced nuclear environmental-permitting reform, one industry advocacy group recommended that the NRC consider developing a generic environmental impact statement (GEIS) for the construction and operation of advanced reactors which would include microreactors [18]. This communication pointed out that a generic impact statement is acceptable under NEPA and has been used by the NRC for a variety of other regulatory activities. Furthermore, a GEIS covering advanced reactors would:

- Acknowledge areas where common environmental impacts have already been effectively addressed in other elements of the NRC review

- Acknowledge areas where issuance of other federal or state environmental permits can mitigate environmental impact

- Credit designs that minimize environmental impact due to the production, design, and safety features of advanced reactors.

In instances where a particular reactor design or site presents unique environmental challenges, those issues can be addressed through the use of a supplemental environmental impact statement (SEIS).

Developing a GEIS for the construction and operation of microreactors would be advantageous by ultimately:

- Focusing environmental-review efforts on the most important aspects of licensing

- Reduce NRC staff resources dedicated to environmental permitting

- Meet the objectives under Executive Order (EO) 13807 and various legislation that seeks to streamline permitting 
- Meet all statutory obligations under both CEQ's and NRC's current environmental regulations.

\section{Recommendation:}

Evaluate the feasibility of developing a GEIS as part of, or in lieu of, site-specific microreactor EIS processes in order to increase the speed, efficiency, and thoroughness of microreactor siting and transport regulatory approvals.

\subsubsection{Site Physical Security}

6.3.4.1 Current Regulations. Physical protection (also called physical security) comprises several various measures that operate together to defend a nuclear facility and nuclear material against sabotage, theft, diversion, and other malicious acts. Physical protection requirements for NRC-regulated nuclear power plants and special nuclear materials are described in 10 CFR Part 73 with Division 5 series regulatory guides (i.e., RGs 5.1-5.88) available to provide interpretive compliance guidance. A graded physical-protection approach is expected consistent with the significance of the facility and involved materials. The NRC establishes regulatory requirements for assessing compliance of physical protection programs while licensees are responsible for providing protection.

Nuclear reactors require physical protection, as do spent-fuel-storage facilities. Physical protection programs include:

1. Threat assessments to determine how much physical protection is enough

2. Physical-protection areas graded to provide defense-in-depth with barriers and controls for the exclusion area, protected area, vital area, and material-access area

3. Intrusion detection to notify a site-security force of potential intruders

4. Intrusion-alarm assessment to distinguish between false or nuisance alarms and actual intrusions and to initiate a response

5. Armed response capabilities to protect public health and safety and the common defense and security by defending nuclear material or a nuclear facility against unauthorized intrusion or attack

6. Regulatory initiatives that ensure domestic safeguards, regulation, guidance, and communications continue to adequately protect nuclear facilities and materials in a changing threat environment.

One protection parameter that is uniquely important to siting is ensuring sufficient area exists at the site to permit adequate security standoff distances. Standoff is the distance to any vital structure or vital equipment that would provide enough space to satisfy the security measures of 10 CFR 73.55 (e.g., protected-area barriers, detection equipment, isolation zones, and vehicle barriers). No publictransportation routes are expected to traverse the site within a standoff distance that is now typically assumed to be 110 meters or more. Additional design features and requirements may be necessary if required standoff distances cannot be satisfied by site layout and established boundaries. Local, state, and federal agencies may provide supplemental offsite-protection assistance as necessary. Physical protection, along with safeguards contingency plans that address nuclear-material accountability, are submitted to NRC according to 10 CFR 73 for approval with the license application. Licensees may subsequently revise physical protection plans without prior NRC approval if those changes do not decrease plan effectiveness. If proposed changes decrease plan effectiveness, the licensees must submit the change to $\mathrm{NRC}$ and request a license amendment. Physical protection plans for LWR plants are protected from public disclosure as safeguards information.

6.3.4.2 Gaps in the Regulations. Deployment scenarios for microreactors create additional challenges regarding physical-security measures. These include staffing of rapid-response forces, physical 
security barriers, and authorized personnel screening. While extensive discussions are being sponsored by Nuclear Energy Institute (NEI) within industry concerning microreactor physical protection, the ultimate responsibility for proposing an adequate solution rests with individual unit designers and owner/operator license applicants. Pursuant to 10 CFR $73.55(\mathrm{~b})(1)$, the physical-security protection program's primary performance objectives are to provide high assurance that activities involving special nuclear material are not inimical to the common defense and security and do not constitute an unreasonable risk to public health and safety. As described in SECY-18-0076 and the related staff requirements memoranda (SRM), "the concept of 'high assurance' of adequate protection found in our security regulations is equivalent to 'reasonable assurance' [of adequate protection] when it comes to determining what level of regulation is appropriate."

In the context of a large LWR, this requirement amounts to preventing significant core damage and spent fuel sabotage. The design-basis threat (DBT) for radiological sabotage is used to assess the capability of the physical protection program - including physical barriers, system design features, and response force - to detect, assess, interdict, and neutralize threats of radiological sabotage. The protection of a facility against the DBT is assessed, in part, by the licensee's ability to protect specific target sets. Given the differences between large LWRs and microreactors, the NRC may need to develop an alternative to significant core damage as a surrogate measure of the level of radiation released to the site boundary by microreactors.

New NRC rulemaking would provide a voluntary, performance-based alternative to the prescriptive requirements 10 CFR $73.55(\mathrm{k})(5)(\mathrm{ii})$, related to the required minimum number of armed responders, and 10 CFR 73.55(i)(4)(iii), related to onsite secondary alarm stations for those advanced reactors that could demonstrate the ability to meet the performance criteria.

\section{Recommendation:}

It is recommended that microreactor suppliers and NRC initiate interactions to precisely delineate the challenges associated with physical protection appropriate to microreactor deployment scenarios and plan for the performance of $R \& D$ and testing that support proposed physical-protection measures in a context of increased siting flexibility and minimal on-site staffing.

\subsubsection{Scaled Emergency Planning}

6.3.5.1 Current Regulations. Emergency plans are required both onsite and offsite at nuclear plants to ensure adequate protective measures are implemented when needed to protect workers and the public in the event of radiological emergency. Federal oversight of emergency planning (EP) at commercial nuclear plants is currently shared by NRC and the Federal Emergency Management Agency (FEMA), with NRC acting as the sole licensing authority.

Key EP requirements for commercial nuclear power plants are contained in 10 CFR 50.47, "Emergency Plans," and Appendix E to Part 50, "Emergency Planning and Preparedness for Production and Utilization Facilities." These requirements were derived from concepts and methodologies contained in NUREG-0396, "Planning Basis for the Development of State and Local Government Radiological Emergency Response Plans in Support of Light Water Nuclear Power Plants" [19]. The regulations and guidance are focused on evaluating 16 radiological-event planning standards, the management of impediments in meeting those standards, and gauging overall public acceptance of a nuclear facility at the proposed site.

The benchmark emergency-planning-zone (EPZ) size now being used by NRC was defined on the basis of large LWR source terms, established evacuation needs, and other protective actions derived from two nominally-sized EPZs: (1) a 10-mile radius plume exposure pathway EPZ, and (2) a 50-mile radius ingestion exposure pathway EPZ. Guidance contained in RG 4.7, "General Site Suitability Criteria for Nuclear Power Stations" [16], further notes that certain site characteristics, and nearby special 
populations like hospitals and prisons, represent a unique impediment in EP and addressing them is a significant regulatory concern.

Nuclear EP requires close cooperation between state and local response agencies in addition to federal involvement. In all cases, early interactions with elected state and local officials and emergencymanagement organizations are expected of licensees, and cooperative working relationships are to be established to ensure effective event response. Although NRC regulations do provide remedies in instances where state and local governments choose not to participate in plant EP responsibilities, significant difficulties in licensing usually accompany adversarial relationships with state and local government authorities. A lack of public confidence in plant safety often surfacing as expressions of concern in off-site emergency planning, particularly for options involving public evacuation.

NUREG-0654/FEMA-REP-1, Rev. 1, "Criteria for Preparation and Evaluation of Radiological Emergency Response Plans and Preparedness in Support of Nuclear Power Plants," offers important guidance to state and local radiological emergency-plan developers regarding "upgraded acceptance criteria." In it, a footnote consistent with the regulatory provisions in $\S 50.47$ states:

These radii are applicable to light water nuclear power plants, rated at $250 \mathrm{MWt}$ or greater. The FEMA/NRC Steering Committee has concluded that small watercooled power reactors (less than $250 \mathrm{MWt}$ ) and the Fort St. Vrain gas cooled reactor may use a plume exposure emergency planning zone of about 5 miles in radius and an ingestion pathway emergency planning zone of about 30 miles in radius. In addition, the requirements for the alerting and notification system (Appendix 3) will be scaled on a case-by-case basis. This conclusion is based on the lower potential hazard from these facilities (lower radionuclide inventory and longer times to release significant amounts of activity for many accident scenarios). The radionuclides considered in planning should be the same as recommended in NUREG-0396/EPA-520/1-78-016.

10 CFR 50.33(g) and 50.47(c)(2) allow EPZs to be determined on a case-by-case basis. For this, applicants are expected to develop technical reports that implement a systematic approach to resizing the EPZ and provide a technical basis supporting the submittal. Technical reports must discuss the rationale for revised EPZ size and identify the licensing-basis events (LBE) used for emergency-planning purposes from the full spectrum of credible accident scenarios applicable to the design. The approach should remain consistent with 10 CFR 50.47 and other current Commission positions, such as those summarized in SECY 97-0020, SECY 03-0047, and SECY 10-0034. The technical report should also elaborate on how safety is increased by the proposed action through greater emphasis on inherent and passive features which, in turn, reduces reliance on EP measures (when compared to an LWR).

The NRC is now preparing to propose changes to its emergency-planning regulations (SECY-18-0103) and specify new alternative EP requirements for small modular reactors (SMRs) and other new technologies (ONT). The new EP requirements and implementing guidance would acknowledge recent technological advancements and other differences from large LWRs inherent in SMRs and ONTs.

The proposed rule would be technology inclusive and provide all existing and future SMR and non-LWR applicants the alternative to develop a performance-based EP program, rather than using the existing, deterministic, EP requirements in 10 CFR 50. This proposed rule does not include within its scope emergency planning, preparation, and response for large LWRs, which for the purposes of this rule are those LWRs that are licensed to produce greater than 1,000 megawatts thermal power, fuel-cycle facilities, or currently operating non-power reactors.

The proposed rule is expected to include the following major provisions: 
- A new, alternative, performance-based EP framework, including requirements for demonstrating effective response in drills and exercises for emergency and accident conditions

- A hazard analysis of any NRC-licensed or non-licensed facility located contiguous to an SMR or ONT that considers any hazard that would adversely impact the implementation of emergency plans

- A scalable approach for determining the size of the plume exposure pathway EPZ

- A requirement to describe ingestion-response planning in the emergency plan, including the capabilities and resources available to prevent contaminated food and water from entering the ingestion pathway.

6.3.5.2 Gaps in the Regulations. The new EP rule, if enacted, would provide increased flexibility for microreactors in meeting EP requirements. The 16 emergency planning standards now contained in 10 CFR 50.47 reflect a plume-exposure EPZ appropriate for a large LWR. These EP requirements may not be compatible with increased microreactor siting independence. The forthcoming NRC EP rulemaking is an opportunity to reset existing requirements to a scalable application commensurate with technology needs. 


\section{Recommendation:}

It is recommended that DPE amd the microreactor community actively engage in the coming EP rulemaking to assure NRC staff and the public are adequately informed of microreactor design-safety approaches and to ensure new rules are optimized to accommodate pertinent microreactor risk factors. Planning standards should be reviewed and changed as necessary to address the lower-risk profiles of microreactors. Table 2 (below) provides some preliminary insight in how planning standards might be adjusted.

Table 2. Microreactor considerations in 10 CFR 50.47 emergency planning standards.

\begin{tabular}{|c|c|}
\hline Planning Standard & Microreactor Considerations \\
\hline $\begin{array}{l}\S 50.47(b)(1) \text { : Assignment of responsibility (organizational } \\
\text { control) } \\
\text { Primary responsibilities for emergency response by the } \\
\text { nuclear facility licensee and by state and local organizations } \\
\text { within EPZs are assigned, emergency responsibilities of } \\
\text { various supporting organizations are specifically established, } \\
\text { and each principal response organization has staff to respond } \\
\text { and to augment its initial response on a continuous basis. }\end{array}$ & $\begin{array}{l}\text { Licensee emergency response } \\
\text { organizational structure is simplified. } \\
\text { Offsite emergency response } \\
\text { organizational structure is simplified with } \\
\text { fewer jurisdictions due to smaller impact } \\
\text { zones. }\end{array}$ \\
\hline $\begin{array}{l}\S 50.47(\mathrm{~b})(2) \text { : Onsite emergency organization } \\
\text { On-shift facility licensee responsibilities for emergency } \\
\text { response are unambiguously defined, adequate staffing to } \\
\text { provide initial facility accident response in key functional } \\
\text { areas is maintained at all times, timely augmentation of } \\
\text { response capabilities is available, and the interfaces among } \\
\text { various onsite response activities and offsite support and } \\
\text { response activities are specified. }\end{array}$ & $\begin{array}{l}\text { Staffing is based on reactor design. } \\
\text { Staffing needs are fewer and required } \\
\text { response times are increased. }\end{array}$ \\
\hline $\begin{array}{l}\S 50.47(b)(3) \text { : Emergency response support and resources } \\
\text { Arrangements for requesting and effectively using assistance } \\
\text { resources have been made, arrangements to accommodate } \\
\text { State and local staff at the licensee's near-site Emergency } \\
\text { Operations Facility have been made, and other organizations } \\
\text { capable of augmenting the planned response have been } \\
\text { identified. }\end{array}$ & $\begin{array}{l}\text { Availability of offsite fire, ambulance, } \\
\text { and other emergency support resources } \\
\text { commensurate with facility risks. } \\
\text { Alternate provisions provided for near-site } \\
\text { Emergency Operations Facility. }\end{array}$ \\
\hline $\begin{array}{l}\$ 50.47(b)(4) \text { : Emergency classification system } \\
\text { A standard emergency classification and action level } \\
\text { scheme, the bases of which include facility system and } \\
\text { effluent parameters, is in use by the nuclear facility licensee, } \\
\text { and State and local response plans call for reliance on } \\
\text { information provided by facility licensees for determinations } \\
\text { of minimum initial offsite response measures. }\end{array}$ & $\begin{array}{l}\text { Four levels (i.e., Notification of Unusual } \\
\text { Event, Alert, Site Area Emergency, and } \\
\text { General Emergency) are reassessed and } \\
\text { revised pursuant to risks, operating } \\
\text { characteristics and safeguards associated } \\
\text { with microreactor technology. }\end{array}$ \\
\hline
\end{tabular}


Table 2. (continued).

\begin{tabular}{|c|c|}
\hline Planning Standard & Microreactor Considerations \\
\hline $\begin{array}{l}\S 50.47(b)(5) \text { : Notification methods and procedures } \\
\text { Procedures have been established for notification, by the } \\
\text { licensee, of State and local response organizations and for } \\
\text { notification of emergency personnel by all organizations; the } \\
\text { content of initial and follow-up messages to response } \\
\text { organizations and the public has been established; and means } \\
\text { to provide early notification and clear instruction to the } \\
\text { populace within the plume exposure pathway Emergency } \\
\text { Planning Zone have been established. }\end{array}$ & $\begin{array}{l}\text { Participating agencies/jurisdictions are } \\
\text { driven by reduced EPZ size. }\end{array}$ \\
\hline $\begin{array}{l}\S 50.47(b)(6) \text { : Emergency communications } \\
\text { Provisions exist for prompt communications among } \\
\text { principal response organizations to emergency personnel and } \\
\text { to the public. }\end{array}$ & $\begin{array}{l}\text { Need for prompt notification and } \\
\text { supporting systems is reduced because of } \\
\text { absence of a significant release of } \\
\text { radioactive material. }\end{array}$ \\
\hline $\begin{array}{l}\S 50.47(b)(7) \text { : Public education and information } \\
\text { Information is made available to the public on a periodic } \\
\text { basis on how they will be notified and what their initial } \\
\text { actions should be in an emergency (e.g., listening to a local } \\
\text { broadcast station and remaining indoors), the principal } \\
\text { points of contact with the news media for dissemination of } \\
\text { information during an emergency (including the physical } \\
\text { location or locations) are established in advance, and } \\
\text { procedures for coordinated dissemination of information to } \\
\text { the public are established. }\end{array}$ & $\begin{array}{l}\text { Information dissemination needs are } \\
\text { significantly reduced due to smaller } \\
\text { plume exposure EPZ. }\end{array}$ \\
\hline $\begin{array}{l}\S 50.47(b)(8) \text { : Emergency facilities and equipment } \\
\text { Adequate emergency facilities and equipment to support the } \\
\text { emergency response are provided and maintained. }\end{array}$ & $\begin{array}{l}\text { Consolidate and reduce need for } \\
\text { Technical Support Center (TSC) and } \\
\text { Emergency Operations Facility (EOF) due } \\
\text { to lessened consequence severity and } \\
\text { emergency response action timing. } \\
\text { Reduce emergency response equipment } \\
\text { needs. }\end{array}$ \\
\hline $\begin{array}{l}\S 50.47(b)(9) \text { : Accident assessment } \\
\text { Adequate methods, systems, and equipment for assessing } \\
\text { and monitoring actual or potential offsite consequences of a } \\
\text { radiological emergency condition are in use. }\end{array}$ & Still required. \\
\hline $\begin{array}{l}\S 50.47(b)(10) \text { : Protective response } \\
\text { A range of protective actions has been developed for the } \\
\text { plume exposure pathway EPZ for emergency workers and } \\
\text { the public. In developing this range of actions, consideration } \\
\text { has been given to evacuation, sheltering, and, as a } \\
\text { supplement to these, the prophylactic use of potassium } \\
\text { iodide, as appropriate. Guidelines for the choice of } \\
\text { protective actions during an emergency, consistent with } \\
\text { federal guidance, are developed and in place, and protective } \\
\text { actions for the ingestion exposure pathway EPZ appropriate } \\
\text { to the locale have been developed. }\end{array}$ & $\begin{array}{l}\text { Limited offsite protective actions due to } \\
\text { small plume exposure EPZ. }\end{array}$ \\
\hline
\end{tabular}


Table 2. (continued).

\begin{tabular}{|c|c|}
\hline Planning Standard & Microreactor Considerations \\
\hline $\begin{array}{l}\$ 50.47(b)(11) \text { : Radiological exposure control } \\
\text { Means for controlling radiological exposures, in an } \\
\text { emergency, are established for emergency workers. The } \\
\text { means for controlling radiological exposures shall include } \\
\text { exposure guidelines consistent with EPA Emergency Worker } \\
\text { and Lifesaving Activity Protective Action Guides. }\end{array}$ & $\begin{array}{l}\text { Still required onsite. Fewer offsite } \\
\text { requirements due to smaller plume } \\
\text { exposure EPZ. }\end{array}$ \\
\hline $\begin{array}{l}\S 50.47(\mathrm{~b})(12) \text { : Medical and public health support } \\
\text { Arrangements are made for medical services for } \\
\text { contaminated injured individuals. }\end{array}$ & $\begin{array}{l}\text { Still required onsite. } \\
\text { Offsite support will decrease due to } \\
\text { smaller impact zone and fewer } \\
\text { jurisdictions. }\end{array}$ \\
\hline $\begin{array}{l}\S 50.47(\mathrm{~b})(13) \text { : Recovery and reentry planning and } \\
\text { post-accident operations } \\
\text { General plans for recovery and reentry are developed. }\end{array}$ & $\begin{array}{l}\text { General plan for reentry and recovery } \\
\text { commensurate with design. }\end{array}$ \\
\hline $\begin{array}{l}\S 50.47(\mathrm{~b})(14) \text { : Exercises and drills } \\
\text { Periodic exercises are (will be) conducted to evaluate major } \\
\text { portions of emergency response capabilities, periodic drills } \\
\text { are (will be) conducted to develop and maintain key skills, } \\
\text { and deficiencies identified as a result of exercises or drills } \\
\text { are (will be) corrected. }\end{array}$ & $\begin{array}{l}\text { Limited scope onsite and participating } \\
\text { offsite agencies/jurisdictions due to } \\
\text { smaller EPZ and reduced spectrum of } \\
\text { design basis events. }\end{array}$ \\
\hline $\begin{array}{l}\S 50.47(b)(15) \text { Radiological emergency response training } \\
\text { Radiological emergency response training is provided to } \\
\text { those who may be called on to assist in an emergency. }\end{array}$ & $\begin{array}{l}\text { Fewer onsite requirements. } \\
\text { Offsite limited to fire/rescue/medical and } \\
\text { affected jurisdiction. }\end{array}$ \\
\hline $\begin{array}{l}\S 50.47(b)(16) \text { : Responsibilities for emergency planning } \\
\text { Responsibilities for plan development and review and for } \\
\text { distribution of emergency plans are established, and planners } \\
\text { are properly trained. }\end{array}$ & $\begin{array}{l}\text { Less effort to maintain plans and program } \\
\text { with offsite responsibilities integrated into } \\
\text { all-hazards planning. }\end{array}$ \\
\hline
\end{tabular}

\subsubsection{Microgrid Reliability}

A microgrid can be defined as a localized electrical-transmission system disconnected from a larger grid system and operated autonomously in response to limited-scope energy needs. Energy suppliers to a microgrid may provide electrical service in island mode (i.e., provide for its own house load without incurring reactor trip), serve a single dedicated customer, or simultaneously tend to multiple customer loads using utility lines operated akin to larger transmission systems as depicted in Figure 4. 


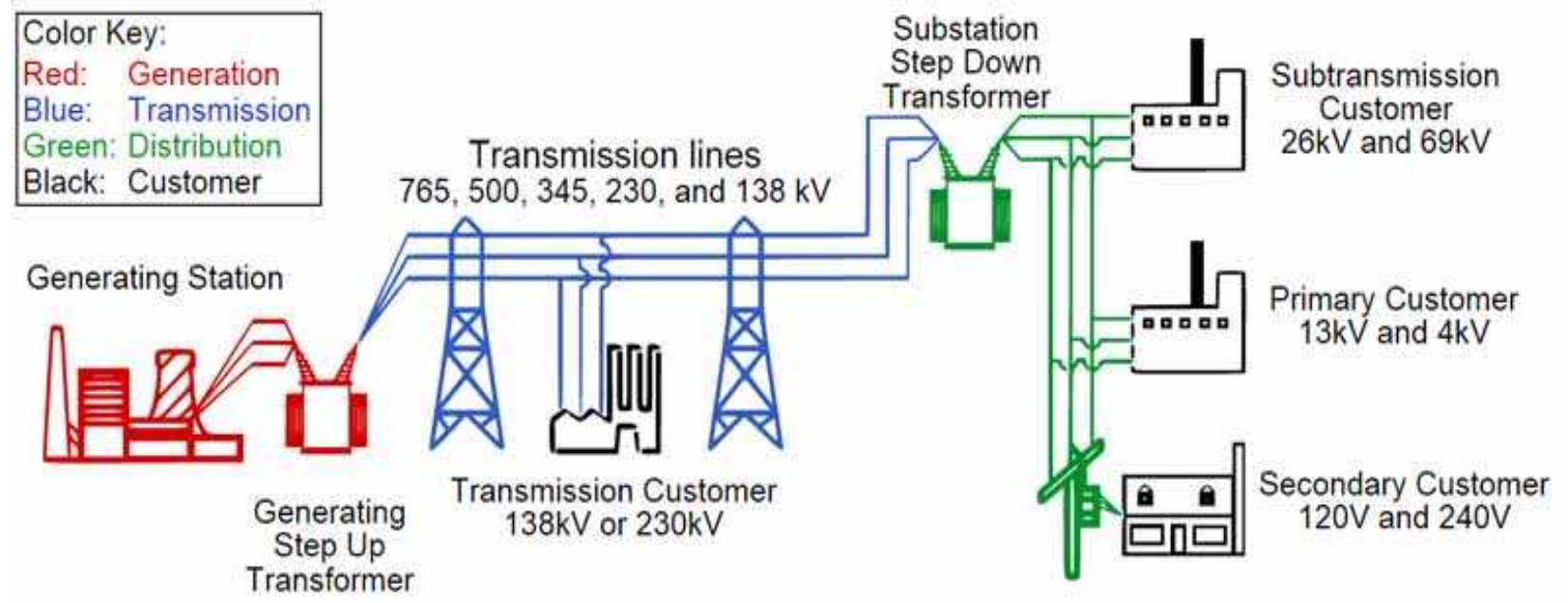

Figure 4. Structure of a basic electricity distribution system.

Regardless of grid size, however, an intricate relationship exists between electrical-grid transmission facilities, distribution networks, and nuclear power plants connected to that grid. Transmission networks generally prefer multiple power-generation resources be available to increase redundancy, respond to fluctuating customer loads, ensure adequate line voltage support, and maintain overall grid stability. Most bulk-power-system problems are never seen by consumers because resilience and redundancy are built into a grid system designed and operated to preclude cascading electrical blackouts. However, when a severe problem on the bulk system does occur, it can cascade through a grid in minutes and produce widespread electrical blackouts.

When a large power-generation resource trips, the transmission system experiences loss of real- and reactive-power support. The grid must react quickly to such a loss because, should multiple contingencies occur, the system may be unable to respond adequately to increasing challenge. Nuclear power plant risk and grid instability are tightly coupled insofar as tripping a nuclear power plant can create grid instability and grid instability can trip nuclear power plants. When considering how grids impact LWRs, most studies focus on loss-of-offsite-power (LOOP) events, during which all offsite power lines leading to the plant are temporarily de-energized. A LOOP event typically results in an automatic reactor scram and actuation of key plant safety systems. Grid-induced unit trips are therefore viewed as a serious nuclear safety concern in LWRs because an increase in grid-related plant trips translates into direct challenges to nuclear safety systems and increased risk of core damage.

Smaller nuclear power stations may be equipped with multiple reactor modules that share a common power-conversion unit (e.g., a steam-turbine generator). If that turbine generator malfunctions, it would likely trigger simultaneous shutdowns of multiple reactor units. This also constitutes a significant challenge to plant safety systems, especially for SSCs responsible for removing decay heat from the core. For all design conditions, core-heat energy that is not utilized by process-heat applications or is otherwise converted into electricity must ultimately be rejected into the surrounding environment. This is a fundamental safety consideration for station blackout (SBO, i.e., loss of plant AC power) and LOOP conditions, both of which must be addressed through appropriate reactor design. Maintaining access to the ultimate heat sink is therefore a major concern when evaluating and qualifying a site.

As small reactors mature for use in microgrids as electrical-power generators, a certain degree of resiliency and reliability will be demanded of those machines. Licensing questions will arise regarding like how alternate (off-site) AC power resource needs will be met in the absence of island-capable microreactor operations. If a nuclear module does not have "black-start" capabilities, are on-site emergency diesel electric generators needed to ensure defense-in-depth reactor safety? 
The issue of redundancy is also noteworthy in grids powered by multiple microreactor modules. When multiple nuclear power plants are relied upon to support grid voltage, the post-trip voltage situation can be worsened when one generating unit trips and causes system voltage to drop into the trip range of a second unit. Then, when the second unit trips, a cascading trip sequence can result. It is therefore critical that grid and plant operators know when they are on the threshold of such a scenario and implement provisions to avoid cascading trips. Given that microreactor designers are proposing to address this contingency using highly automated systems that have yet to be demonstrated as adequately safe in nuclear plant applications, development and demonstration of the reliability, precision, and accuracy of this emerging technology should be treated as an important future licensing concern.

6.3.6.1 Current Regulations. When a microgrid serves area customers, it may be necessary to consider requirements of the Federal Energy Regulatory Commission (FERC). FERC is an independent government agency that regulates interstate transmission of electricity, natural gas, and oil within the U.S. (https://www.ferc.gov/). Interstate transmission and bulk sales of electricity are regulated by FERC, as are applications for electric transmission project applications. FERC also protects high-voltage transmission systems by enforcing mandatory reliability standards.

The Energy Policy Act of 2005 (Public Law 109-58, August 8, 2005) called for creation of an Electric Reliability Organization (ERO) to develop mandatory electric reliability standards within the U.S. In 2006, 1,600 bulk power system owners and operators (i.e., North American Electric Reliability Corporation, NERC) were designated a "self-regulatory organization" by FERC to address the interconnected and international nature of bulk-electrical-power grids. Shortly thereafter, NERC filed a set of mandatory reliability standards with FERC and made similar filings with Canadian authorities. In June 2007, 83 NERC reliability standards were approved by FERC, making them legally enforceable for U.S. bulk power systems (additional reliability standards have been added since that time).

NERC grid-reliability standards are derived from the following guiding principles:

Reliability Principle 1-Interconnected bulk electric systems shall be planned and operated in a coordinated manner and perform reliably under normal and abnormal conditions as defined in NERC Standards.

Reliability Principle 2-Frequency and voltage of interconnected bulk electric systems shall be controlled through balance of real and reactive power supply and demand.

Reliability Principle 3-Information necessary for planning and operation of interconnected bulk electric systems shall be available to those responsible for planning and reliably operating the systems.

Reliability Principle 4-Plans for emergency operation and interconnected bulk electric system restoration shall be developed, coordinated, maintained and implemented.

Reliability Principle 5-Facilities for communication, monitoring, and control shall be provided, used, and maintained for the reliability of interconnected bulk electric systems.

Reliability Principle 6-Personnel responsible for planning and operating interconnected bulk electric systems shall be trained, qualified, and responsible for actions.

Reliability Principle 7-Security of the interconnected bulk electric systems shall be assessed, monitored, and maintained on a wide-area basis. 
As already discussed, LOOP caused by loss of grid generation capacity can be a major safety concern for a nuclear plant. Because of this, FERC/ERO transmission-reliability requirements intertwine significantly with the public-safety and regulatory-oversight mission of NRC at a nuclear power plant.

The current fleet is heavily dependent on the electrical grid to provide preferred power to station emergency equipment, support plant operations, and maintain compliance with NRC license conditions. Because offsite power specifications are tight, these plants are quite susceptible to grid voltage variations and frequency swings. To help ensure safe plant operations, operators need to know grid status in real-time and maintain response contingencies to changes in offsite power supply. Since loss of large capacity generation resources will likely remain a major contingency for transmission operators and nuclear plants connected to the grid, transmission-system operators must be aware of nuclear power plant requirements and employ methods and procedures that will satisfy nuclear plant safety requirements.

A mandatory FERC standard addresses coordination between nuclear power plants and the transmission system [20]. Standard NUC-001-3 states:

This standard requires coordination between Nuclear Plant Generator Operators and Transmission Entities for the purpose of ensuring nuclear plant safe operation and shutdown.

6.3.6.2 Gaps in the Regulations. While application of this and other FERC standards remains to be confirmed in isolated microgrid applications of nuclear power technology, the underlying intent of protecting nuclear units from offsite-induced transients is relevant for all anticipated applications. Involved entities must be aware of, plan for, and operate according to the needs of the nuclear power generator, the electrical grid, and customers. Interface agreements between nuclear power generators and microgrid operators will be needed to ensure post-trip voltages are adequately maintained and to assure nuclear license requirements are satisfied.

\section{Recommendation:}

The requirements relationship between transmission system performance and microreactor safety remains to be defined for microgrid applications. While smart-grid technology and automated reactivity controls are tools generally cited as appropriate to address this relationship, this technology is new and remains to be demonstrated as adequate for nuclear safety. It is recommended that a regulatory technology development analysis be performed to define how microgrid control technology should be developed to complement microreactor safety and NRC licensability. A goal of this analysis is to assure grid transients do not imperil safety related SSCs and increase risk of core damage. Determinations on the extent FERC reliability standards should apply to microreactor-powered microgrids are also recommended. Since microreactors may intermittently connect to larger grids at certain times, FERC standards concerning communications and switching requirements of dual-mode nuclear plant operations should also be addressed.

\subsubsection{Industrial Collocation}

Baseload electric-power generation is the traditional commercial market of the nuclear fleet. Other market niches are emerging for microreactor technologies, however. While suppliers sometimes claim their designs are great candidates for remote installations and other difficult-to-address energy applications, the very nature of being a portable, long-lived energy resource that leaves virtually no carbon footprint invites their consideration in many situations impossible to address with larger nuclear plants. 


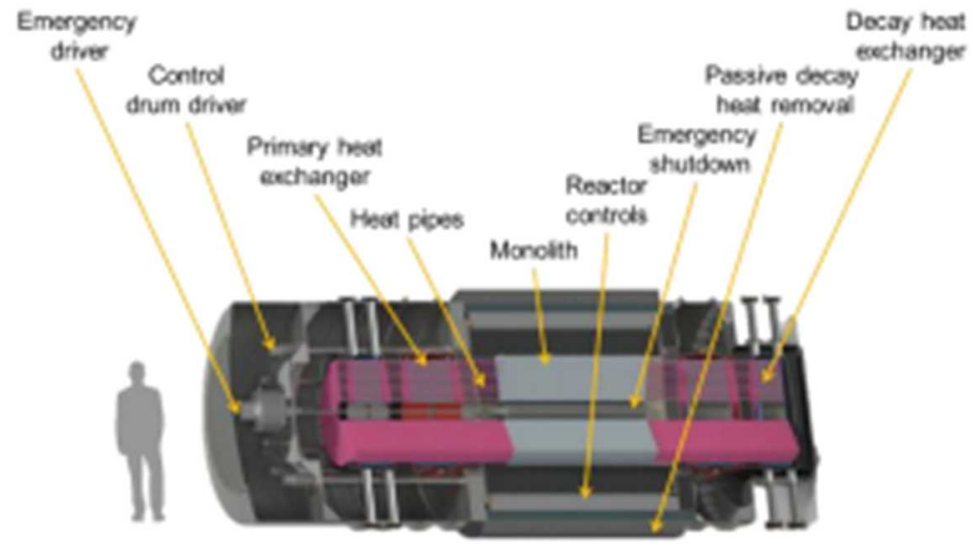

Figure 5. The Westinghouse eVinci microreactor design concept.

Given a reactor module sized similar to that shown in Figure 5, potential examples of new microreactor energy applications include:

- Cogeneration steam supply for electricity and industrial processes

- District heating

- Seawater desalination

- Oil and tar sands extraction

- Production of biofuels and chemical feedstock

- Hydrogen production

- Off-grid power for isolated systems like military installations, developing nation, mineral-mining operations, communication bases, etc.

- Backup (baseload) power for renewables like wind or solar plants

- Secure power resource for critical infrastructure elements like computer-server farms

- Replacement of aging fossil plants.

The industrial suitability of using an individual microreactor design will largely be a function of outlet temperature capabilities of the reactor. Temperature requirements for a few industrial processes, along with the temperature capabilities of LWR, high temperature gas-cooled, and sodium fast reactor technologies, are shown in Figure 6. 


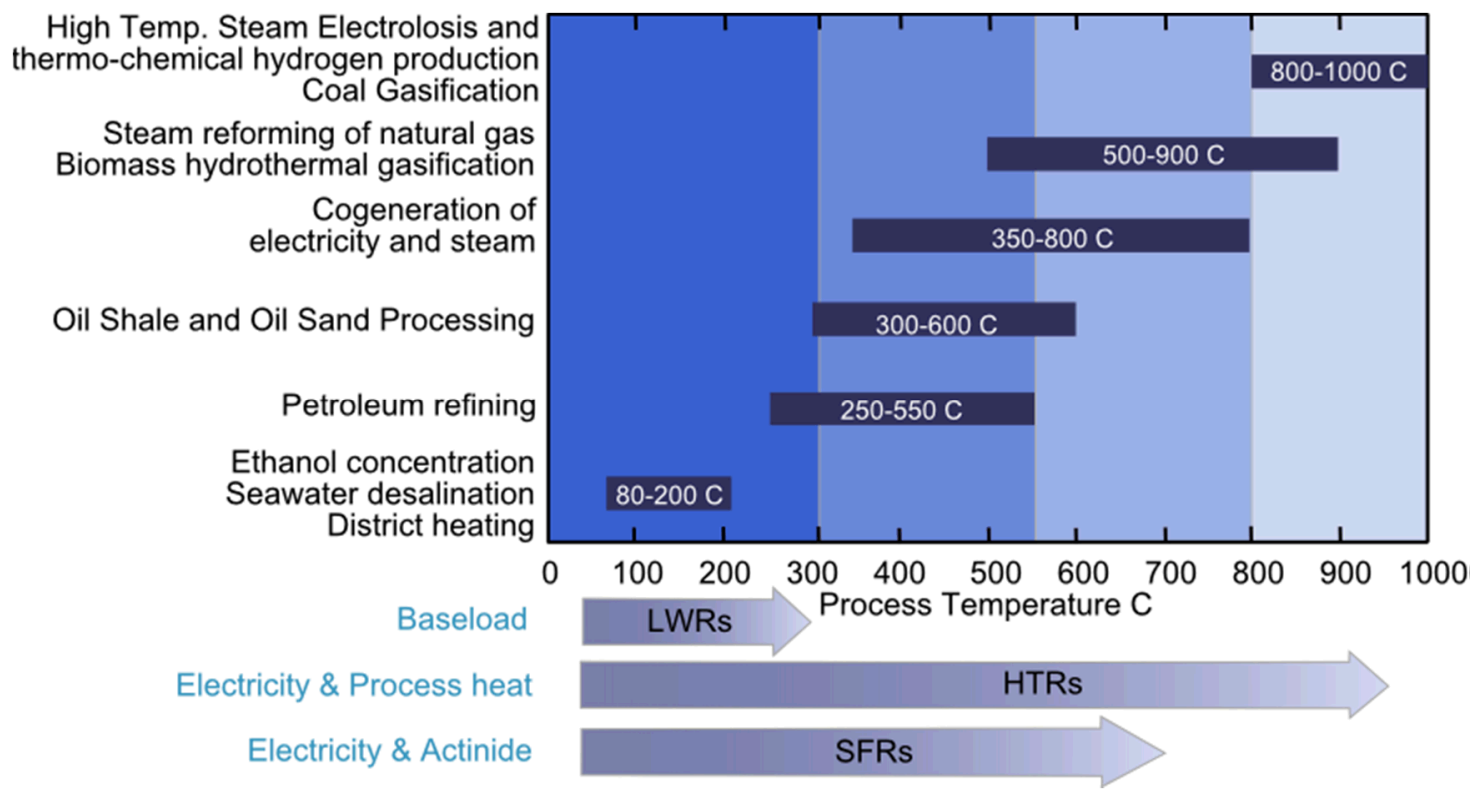

Figure 6. Some typical industrial heat requirements by industry type and exit temperature.

Historically, power-generation LWRs were sited at considerable distance from industry customers to isolate industrial and physical risks from each other. This also operated to separate regulatory obligations of the nuclear facility from corollary obligations at non-nuclear industrial facilities. However, because collocated nuclear-heat suppliers will need to be in close physical proximity (maybe a few hundred meters) to industrial customer targets, current regulatory safety assessment models must be adapted to accommodate nuclear and non-nuclear risks at collocated and conjoined facilities. This issue could be further complicated if a microreactor site qualifies as a "brownfield" setting (i.e., where pre-existing chemical contaminations might be present) or a regulated infrastructure component (such as cooling water intake or a wastewater treatment facility) is shared with an industrial and/or municipal partner.

6.3.7.1 Current Regulations. The nuclear island of a microreactor installation will need to conform to the terms and conditions of its NRC-issued license. These conditions normally would not be binding on an adjacent non-nuclear facility customer. However, depending on the nature of industries and associated risks involved, a web of local, state, and federal regulatory authorities could encompass both facilities. A systematic means is needed to clearly and reliably establish regulatory boundaries at these collocated facilities.

The issue of "jurisdictional authority" at conjoined nuclear and non-nuclear facilities can be addressed through comprehensive regulatory-compliance planning. Example compliance issues that must he considered in regulatory-compliance planning include:

- Real-time ambient-air monitoring and stack-discharge abatement measures

- Solid-, hazardous-, and radioactive-waste management

- Wastewater treatment and discharge monitoring and control

- Access to compliance monitors and inspection points

- Subsurface-soil and groundwater investigations and/or remediation

- Emergency response planning, training, and drills

- Spill cleanup and issues associated with legacy contamination. 
Given the spectrum of configuration options likely to be included in a microreactor designcertification (DC) application, regulatory boundaries need to be established to streamline the licensing process and promote greater design independence from siting.

Historically, commercial nuclear power plants licensed under 10 CFR 50 covered the entire plant. Under 10 CFR 52, NRC expects a nuclear power plant license application to include a complete design for the entire facility (including non-nuclear balance-of-plant components). Paragraph 52.47(a) of 10 CFR states general requirements for the DC Final Safety Analysis Report (FSAR) as:

(a) The application must contain a final safety analysis report (FSAR) that describes the facility, presents the design bases and the limits on its operation, and presents a safety analysis of the structures, systems, and components and of the facility as a whole, and must include the following information:

(1) The site parameters postulated for the design, and an analysis and evaluation of the design in terms of those site parameters;

(2) A description and analysis of the structures, systems, and components (SSCs) of the facility, with emphasis upon performance requirements, the bases, with technical justification therefor, upon which these requirements have been established, and the evaluations required to show that safety functions will be accomplished. It is expected that the standard plant will reflect through its design, construction, and operation an extremely low probability for accidents that could result in the release of significant quantities of radioactive fission products. The description shall be sufficient to permit understanding of the system designs and their relationship to the safety evaluations. Such items as the reactor core, reactor coolant system, instrumentation and control systems, electrical systems, containment system, other engineered safety features, auxiliary and emergency systems, power conversion systems, radioactive waste handling systems, and fuel handling systems shall be discussed insofar as they are pertinent.

10 CFR 52.47(a) notes that a design certification must include:

(24) A representative conceptual design for those portions of the plant for which the application does not seek certification, to aid the NRC in its review of the FSAR and to permit assessment of the adequacy of the interface requirements in paragraph (a)(25) of this section;

(25) The interface requirements to be met by those portions of the plant for which the application does not seek certification. These requirements must be sufficiently detailed to allow completion of the FSAR;

Paragraph (c) of 52.47, adds design certification application content requirements by requiring:

(3) An application for certification of a modular nuclear power reactor design must describe and analyze the possible operating configurations of the reactor modules with common systems, interface requirements, and system interactions. The final safety analysis must also account for differences among the configurations, including any restrictions that will be necessary during the construction and startup of a given module to ensure the safe operation of any module already operating.

These requirements indicate NRC will exert jurisdiction over the nuclear steam-supply system, support systems, and balance-of-plant systems (e.g., energy-conversion systems). Up to now, this position 
has been supported by installations that have those systems entirely within a discrete site boundary surrounded by a security perimeter fence.

6.3.7.2 Gaps in the Regulations. There may be alternative ways of defining the NRC jurisdictional boundary other than on the basis of a site perimeter or security fence. 10 CFR 52 requires the FSAR to sufficiently describe associated systems so as to permit understanding of systems design and their relationship to safety evaluations. These systems can be expected to always include the reactor core, reactor-coolant system, instrumentation and control systems, electrical systems, containment systems, engineered safety features, auxiliary and emergency systems, a power-conversion system, radioactivewaste-handling systems, and fuel-handling systems. These systems are to be discussed in the FSAR insofar as they are pertinent to the safety evaluation; the key here is to consider "insofar as they are pertinent" - a state-of-art term that could be redefined on the basis of emerging microreactor design safety philosophy.

The challenge for a microreactor applicant will be to describe enough of the plant and its interfaces so as to exclude (offsite) customer energy demand systems while yet demonstrating sufficient protections are in place to provide a reasonable assurance that the nuclear plant will remain safe even for transients and events that may be initiated through the connected systems. Clearly, NRC will retain regulatory authority over all plant SSCs that are relied upon to perform safety-related or risk-significant functions. Energyconversion systems located within the protected site boundary (and controlled by nuclear plant operators) might be considered "integrated within the nuclear facility" and would also likely remain subject to NRC jurisdictional authority. However, an energy-conversion system that is separate from the nuclear island and located outside the protected area boundary (using a controllable energy-transfer system interface) might be excluded from nominal NRC regulatory scope provided certain safety-based assurances are demonstrated.

While an obvious starting point for the jurisdictional boundary between the nuclear facility and industrial facility might be the physical plant site boundary or a protected-area boundary (i.e., the security fence), it will also be necessary to define boundaries at the systems level. Certain plant systems will traverse physical barriers and/or site boundaries and these systems will need an established interface that can be analyzed for safety in a DC or COL application. This safety analyses will describe bounding assumptions concerning balance-of-plant initiated transients and set appropriate interface requirements that must be met for any process connections by external customers. Interface requirements may take the form of process limits or as equipment-design requirements.

Recommendation:

It is recommended that a regulatory basis white paper be developed addressing how microreactor boundaries for the site, $D C$, and at the systems level could be established and monitored between nuclear and non-nuclear facilities (e.g., industries and municipalities). The analysis should consider:

1. The jurisdictional area to be protected under NRC security requirements in 10 CFR 73. Section 2 of 10 CFR 73 contains requirements that protect special nuclear material at fixed sites by requiring vital areas and material-access areas to be located within a protected area and a nuclear-facility boundary encompassing all areas included within the plant's protected area.

2. Identify appropriate nuclear-facility design requirements and associated interface requirements that must be satisfied to ensure transients or incidents involving the industrial facility cannot create conditions outside the safety analyses envelope of the nuclear facility. 


\section{Technical readiness concerns that may impact the establishment of systems-level jurisdictional boundaries}

The white paper should be developed to inform NRC staff and serve as input for new guidance on establishing jurisdictional boundaries at collocated facilities.

\section{REFERENCES}

1. NEI, 2019, Cost Competitiveness of Stationary Microreactors for Enduring Locations, NEI Technical Report, Final Draft, Nuclear Energy Institute, March 28, 2019.

2. NEI, Addressing the Challenges with Establishing the Infrastructure for the front-end of the Fuel Cycle for Advanced Reactors, Jan 2018.

3. DSC, 2016, Task Force on Energy Systems for Forward/Remote Operating Bases, Final Report, Department of Defense for Acquisition, Technology, and Logistics - Defense Science Board, August 1, 2016.

4. NRC RG 1.232, Guidance for Developing Principal Design Criteria for Non-Light-Water Reactors, Regulatory Guide 1.232, Rev 0, U.S. Nuclear Regulatory Commission, April 2018, ADAMS Accession No. ML17325A611

5. NEI 18-04, Modernization of Technical Requirements for Licensing of Advanced Reactors, Risk-Informed Performance-Based Technology Inclusive Guidance for Advanced Reactor Licensing Basis Development, NEI Technical Report 18-04, Rev 0, April 2019.

6. Nichol, M, 2018, Roadmap for the Deployment of Microreactors for US Department of Defense Domestic Installations, NEI Technical Report, Nuclear Energy Institute New Reactor Deployment, October 4, 2018.

7. NRC, NUREG/BR-0298, Nuclear Power Plant Licensing Process, NUREG/BR-0298, Rev 2, U.S. Nuclear Regulatory Commission, July 2009, ADAMS Accession No. ML042120007.

8. NRC, NUREG/BR-0468, Frequently Asked Questions about License Applications for New Nuclear Power Reactors, NUREG/BR-0468, U.S. Nuclear Regulatory Commission, December 2009, ADAMS Accession No. ML100470391 and ML100470394.

9. NRC, RG 1.70, Rev. 3, Standard Format and Content of Safety Analysis Reports for Nuclear Power Plants (LWR Edition), November 1978, ADAMS Accession No. ML011340072.

10. Department of Defense, Defense Science Board, Task Force on Energy Systems for Forward/Remote Operating Bases, August 1, 2016.

11. NUREG/CR-6361, Lichtenwalter, JJ, Bowman, S.M., DeHart, M.D., and Hopper, C.M., Criticality Benchmark Guide for Light-Water-Reactor Fuel in Transportation and Storage Packages, ORNL/TM-13211, Oak Ridge National Laboratory, March 1997.

12. Owusu, D., INL Summer 2018 Report (draft), Regulatory and Licensing Strategy for Microreactor Technology, August 2018.

13. NRC Backgrounder, "Transportation of Spent Fuel and Radioactive Materials," https://www.nrc.gov/reading-rm/doc-collections/fact-sheets/transport-spenfuel-radiomats-bg.html

14. Moe, W.L., 2013, Site Suitability and Hazard Assessment Guide for Small Modular Reactors, INL/EXT-13-29749, Idaho National Laboratory, October 2013.

15. NRC RG 4.2, Rev 3, Preparation of Environmental Reports for Nuclear Power Stations, U.S. Nuclear Regulatory Commission, September 2018, ADAMS Accession No. ML18071A400. 
16. NRC RG 4.7, Rev 3, General Site Suitability Criteria for Nuclear Power Stations, U.S. Nuclear Regulatory Commission, March 2014, ADAMS Accession No. ML12188A053.

17. NRC RG 1.232, Guidance for Developing Principal Design Criteria for Non-Light-Water Reactors, U.S. Nuclear Regulatory Commission, April 2018, ADAMS Accession No. ML17325A611.

18. ClearPath, 2019, “Advanced Nuclear Environmental Permitting Reform," Correspondence to K. Svinicki, Chariman, NRC, from R. Powell, Exec, Dir, ClearPath, February 19, 2019, ADAMS Accession No. ML19059A426.

19. NRC NUREG-0396, Planning Basis for the Development of State and Local Government Radiological Emergency Response Plans in support of Light Water Nuclear Power Plants, EPA 520/1-78-016, December 1978, ADAMS Accession No. ML051390356.

20. FERC, NUC-001-3, "Nuclear Plant Interface Coordination," https://www.nerc.com/pa/stand/Pages/ReliabilityStandardsUnitedStates.aspx?jurisdiction=United $\% 2$ $\underline{\text { OStates }}$ 


\section{Appendix A}

\section{Microreactor Siting Permit-by-Rule}

\section{A Proposal for Streamlined Regulatory Site Acceptance}

Effective and timely characterizations and regulatory acceptance of a site for construction and operation of a microreactor could be a significant challenge under current regulatory requirements. Construction, operations support, assessing impacts to the surrounding environment, and mitigation of events are matters of concern in site-permitting. Technical topics to be evaluated during siting include (but are not limited to) geotechnical properties, geological and seismic hazards, climatology and meteorology, water resources, vulnerability and sensitivities of surrounding populations and environmental features to radionuclide releases, socioeconomic effects, and aesthetics. Additional examinations include topography and factors that influence plant construction, security, transportation, and decommissioning.

Because microreactors are assumed to share commonalties in small size, enhanced safety, automated response, and design integration, these shared features may provide a basis to reset existing sitepermitting processes and relax the burden of site characterization and acceptance for microreactor designs that meet certain minimum criteria. Assuming significant microreactor accident consequences will be shown to be much more improbable and benign when compared to the current fleet, establishing a "permit-by-rule" (PBR) option for qualified microreactor designs may be one way to approach streamlining the microreactor site permitting process.

The PBR approach is an optional permitting provision many state and federal government agencies used for certain types of regulated activities that are relatively common and generally well characterized. These are activities that still require permits but can be routinely managed by regulatory authorities. The notion of PBR is often used to permit regulated air emissions that exert relatively low impacts on the surrounding area. The concept is founded on rules that can be well-established for the regulated activity, define qualifying applicants, standardize limitations and acceptance criteria for sources operating under the PBR, and impose clear operational requirements and conditions that always include reporting and record-keeping. Many PBR requirements resemble those found in traditional facility permits and licenses written expressly for a specific facility emission source. The great advantage in using a PBR process is that it allows applicants and regulators alike to escape much of the paper-permitting process that accompanies a dedicated permit-issuance actions while still effectively controlling the construction and operation of routine regulated activities.

If very small potential source terms and appropriately high levels of safety can be demonstrated by developers during the design certification process in connection with microreactor technology, a PBR approach may be a suitable template for quickly and reliably qualified and permitting microreactor installation site. If enough confidence can be generated in the robust safety of a design operated according to rigorous established norms, the nature of an acceptable site could be predefined as a function of microreactor design and (conditionally) accepted in advance before any individual specific site has been identified. Applicants would know in advance that NRC will issue a permit for certain types of sites so long as those sites meet conditions of applicability and service as specified in the PBR. Transient and/or semi-permanent sites could also be addressed as a subset of a PBR.

\section{Early Site Permitting}

A PBR siting process could be established as an option under NRC's early site permitting (ESP) program. The ESP is a licensing option already authorized under 10 CFR Part 52 Subpart A and offers applicants a means by which regulatory approval for a prospective site can be secured without having to 
specify the precise reactor design that will be installed at the site. At this time, the ESP process is focused on examining site safety, environmental characteristics, and emergency preparedness measures that are somewhat independent of specific reactor design elements; it does this by using a plant parameter envelope (PPE, see below for further discussion). When the process is completed, the ESP program allows applicants to "bank" acceptable sites up to 20 years before construction begins. This reduces licensing uncertainty and allows applicants time to resolve issues both at the site and in plant design.

A safety evaluation report is used to document staff conclusions about whether there is reasonable assurance that a specific ESP site can safely host a nuclear power reactor as described in the PPE. The report also contains preliminary determinations regarding site emergency planning measures. The level of detail contained in the safety evaluation report is related to the extent of information provided by the applicant-i.e., a limited amount of information submitted to NRC for assessment will yield lesscomprehensive staff findings.

Early site permitting is a well-defined process, with extensive compliance guidance available to applicants. The program works with a generalized reactor-plant description to support more detailed assessments of a proposed site. In general, it is reasonable to assume the ESP portion of a combined license application (i.e., starting from initial site characterization work and proceeding through receipt of an approved early site permit from NRC) done according to current guidance will take up to 5 years to complete.

\section{Plant Parameter Envelope}

The PPE is a set of reactor and owner-engineered parameters that define important bounding characteristics relative to an expected reactor design. PPE values are intentionally general in nature, with specific design parameters encompassed by bounds set by the PPE.

There is no explicit regulatory reference in 10 CFR 52.17(a)(1)(i)-(iii) and 52.79(b)(1)(2) to an applicant's use of the PPE. When an applicant looks at a specific site, the regulation in 10 CFR 52.17(a)(1)(i) requires an ESP applicant to describe the specific number, type, and thermal-power level of the facilities or range of facilities that the applicant plans to deploy at the proposed location. Although regulations do not expound on how PPEs are used, NRC has decided that the PPE approach is an acceptable way of meeting Part 52.17(a)(1). [1,2]

To be relevant in a PBR application, the PPE would likely need to be expanded to include more than is currently expected in a ESP application. Depending on commonalities in safety design, the expanded PPE could encompass multiple microreactor design types. For a PPE to serve as a plant PBR input, however, it would need to focus on safety-significant structures, systems, and components and other risk factors of siting concern. In order to drive the PPE closer to a risk-informed emphasis, the expanded list of PPE items could be prioritized on the basis of importance to safety and binned in graded tiers to help balance and direct characterization and assessment efforts towards factors of greater safety influencei.e., PPE risk factors with lessor influence to site safety would be treated with less rigor in ensuing safety assessments.

One example of a top-tier PPE item might involve the need for an exclusion area boundary (EAB) immediately around the microreactor module. EABs will be required for purposes of plant security and to mitigate potential radiological dose to the public. Minimum EAB requirements would be specified in the PPE as a key site-acceptance requirement, and any location that could not provide adequate EAB distances would be disqualified from consideration under the PBR allowance. On the other hand, prospective sites that do meet minimal EAB requirements (along with other mandatory PPE requirements) would be pre-determined to be acceptable under the applicable PBR requirement and can presume a permit is available for issuance without incurring additional evaluation or assessment.

Other PPE parameters likely to retain a significant priority in a siting PBR risk assessment include seismic activity, water resources, meteorological characteristics, and climatological effects on operations. 
Factors that may be less critical to microreactor safety might include offsite power availability, construction work force availability, and off-site emergency response capabilities.

\section{Site Parameter Envelope}

NRC site-assessment techniques presume a site that will undergo a highly detailed safety and security evaluation to determine acceptability. The process does not provide for using a generalized site-parameter envelope (SPE) as allowed for PPEs in the ESP program. However, an exception does exist in 10 CFR 52, Subpart B, which discusses requirements granting a standard design certification (DC) for nuclear power facilities.

10 CFR 52.47 of Subpart B discusses technical contents of a DC application insofar as:

(a) The application must contain a final safety analysis report (FSAR) that describes the facility, presents the design bases and the limits on its operation, and presents a safety analysis of the structures, systems, and components and of the facility as a whole, and must include the following information:

(1) The site parameters postulated for the design, and an analysis and evaluation of the design in terms of those site parameters;

And,

(2)(iv)The safety features that are to be engineered into the facility and those barriers that must be breached as a result of an accident before a release of radioactive material to the environment can occur. Special attention must be directed to plant design features intended to mitigate the radiological consequences of accidents .... The applicant shall perform an evaluation and analysis of the postulated fission product release, using the expected demonstrable containment leak rate and any fission product cleanup systems intended to mitigate the consequences of the accidents, together with applicable postulated site parameters, including site meteorology, to evaluate the offsite radiological consequences.

10 CFR 52.47(a) requires identification of key site parameters important to nuclear plant operation and safety for a DC assessment. Since potential risks and consequences associated with microreactors will likely impose far fewer demands upon a site than do large LWRs, this increase in margin may be applied to create greater site independence and allow the use of SPE. Depending on the sensitivities associated with SPE margins, a basic site safety assessment could be done on to define a hypothetically acceptable site defined based on an acceptable bounding SPE.

\section{Development of a PBR}

A PBR site-permitting approach would be based on performing a safety assessment between a design-oriented PPE and a hypothetical SPE. Examinations would consider fundamental strengths, vulnerabilities, and sensitivities of the hypothetical host site (as defined by the SPE) and consider margins required of the SPE to maintain safety. Uncertainties and errors in the assessment would be addressed by increasing associated safety margins.

Major steps involved in establishing a microreactor PBR site-permitting program include:

- Defining a bounding design PPE (with margins) focused on support to operations and safety. PPE boundaries would be clearly defined and set as a mandatory requirement for construction, operation, and decommissioning under the PBR.

- Defining a bounding SPE (with margins) that emphasizes important plant design-safety parameters. The underlying basis for establishing SPE boundaries would address what is needed of a site to 
satisfy the design PPE. Individual SPE characterization elements could be applied in a graded manner using appropriate risk-informed, performance-based methods.

- A safety assessment would then be done using the design PPE information and a hypothetical site defined based on an SPE. Sensitivity studies would define allowable margins in relationships important to safety.

- PBR site acceptance criteria would be established based on PPE/SPE assessment results. A rule would be published that allows future applicants the opportunity to install micro-reactor units described by the PPE at sites that are found to meet essential SPE criteria.

- The PBR would contain permit conditions, reporting and recordkeeping requirements required of licensees. These conditions and requirements would include those developed under the DC process and the PBR safety assessment. Violations of PBR condition would revoke the PBR permit and force cessation of licensee operations.

\section{Considerations in PBR Development}

The PBR approach would not seek to reduce levels of existing public safety nor eliminate the need for physical protection. Instead, the process would target reduction in bureaucratic burdens associated with site permitting and increase siting independence. A certified microreactor design will be required to support PPE development. Safety margins would need to be demonstrated for covered designs under all conditions to assure unknowns and uncertainties in the PBR assessment are adequately covered.

Proposed sites would still need some level of field characterization and confirmation that SPE conditions and criteria are met. Incompatibilities between the PBR SPE and an actual site might require mitigation; the PBR process may need to accommodate exceptions and contingencies for deficient sites. Sources of uncertainty in site field characterization need to be understood and addressed in the safety assessment process.

A site permitting program using a PBR approach represents a major break in the way nuclear facilities are deployed in the U.S. Many of the benefits resulting from a PBR site permitting process are aligned with increasing the clarity of requirements associated with site acceptance and speeding regulatory acceptance of non-problematic sites. Much of this benefit will be lost, however, at locations that have problems meeting important SPE requirements or require extensive field investigations and corrective actions to bring them to PBR compliance. PBR applicants would bear the risk that a site initially accepted under a PBR site might later be found to fail key PBR parameters.

Important issues to consider when considering the PBR site permitting option include:

- The detail required in definition of a PPE and SPE in order to support a PBR safety assessment.

- The level of confidence required in site field-characterization information.

- The approach to be used to address gaps and outliers in parameter envelope information.

- Methodologies that support a safety assessment based on bounding SPE and PPE elements.

- Establishing conservative margins of acceptance.

- Acceptable means for mitigating key envelope parameters that exceed the bounds of the PBR; this concern may be important in special circumstances such as sites that have experienced a natural disaster. Special regulatory treatment of such circumstances may merit consideration under a PBR approach.

Streamlining site evaluations and permitting from years-long evaluation processes to one that can be completed in days or weeks is a major undertaking that will require substantial time and resources to complete. Exactly how much time and effort will be required depends significantly on how far newly proposed approaches and assessment tools depart from established precedents. Relatively small regulatory 
framework changes (such as adjusting Commission policies, clarifying existing rules, and updating existing guidance), might be accomplished in a few months. However, "tweaking" existing would likely retain many of the constraints and impediments that work against dramatic increases in siting independence.

Because no commercial microreactor has yet been built, there is little track record upon which to base the viability of a PBR approach in nuclear reactor siting. While extensive testing and qualification will be done by developers, it cannot yet be confirmed whether these largely "paper designs" will actually live up to their billing in terms of safety, portability, and reliability. Prototypes will be the means by which microreactors demonstrate their functionality and validate proposed solutions that include siting. Lacking demonstrated proof of greatly enhanced safety, reactor site permitting will likely remain subject to current regulatory standards and procedures which require in-depth field data collection and conservative site safety assessments.

\section{Appendix References}

1. Correspondence from J.E. Lyons, Dir, NRC/NRR, to R.L. Simard, Nuclear Energy Institute, "Resolution of Early Site Permit Topic 6 (ESP), use of Plant parameter Envelope (PPE) Approach,", February 5, 2003, ADAMS Accession No. ML030230071.

2. NEI, 2012, "Industry Guideline for Developing a Plant Parameter Envelope in Support of an Early Site Permit," NEI 10-01 (Rev 1), Nuclear Energy Institute, May 2012, ADAMS Accession No. ML12144A429. 